\title{
Nitrile Elastomer/LDH Composites with Varying Mg/Al Ratio, Curing, Nanoparticles Dispersion and Mechanical Properties
}

\author{
Magdalena Lipińska
}

Additional information is available at the end of the chapter

http://dx.doi.org/10.5772/intechopen.68384

\begin{abstract}
Layered double hydroxides (LDHs) tend to be a promising material in the field of polymer nanocomposites because it possesses unique chemical and structural properties. The novelty of layered double hydroxides (LDHs) comparing to other conventional fillers is connected with possibility of surface functionalization by introduction of various organic species into an interlayer area. Organic modifiers could act not only as intercalation promoters but also have additional functions such as UV stabilizers, anti-aging substances, pigments, antimicrobial, and antifungal activity. Additionally, in the case of nitrile elastomers, layered double hydroxides (LDHs) could play role as curing substances, reinforcing fillers, and improve mechanical, barrier and thermal properties of rubber products. The purpose of our experimental work was to examine the effect of Mg-Al-LDHs on the crosslink density and properties of nitrile rubber. Various LDHs containing, respectively, 30, 63, $70 \mathrm{wt} \%$ of magnesium were applied as a curing system for carboxylated acrylonitrile-butadiene rubber (XNBR) composites prepared by melt compounding methods. The influence of ionic liquids containing saccharinate, acesulfamate ions on the curing reactions and properties of rubber was investigated.
\end{abstract}

Keywords: nanocomposites, layered double hydroxides (LDHs), elastomers, carboxylated nitrile butadiene rubber (XNBR)

\section{Introduction}

\subsection{Layered double hydroxides synthesis, structure and modification}

In commercial application, elastomers are mixed both with vulcanizing additives, sulfur, and the most popular crosslinking activators such as zinc oxide and fillers, commonly 
silica and carbon black are added. Reinforcing effect, improvement in mechanical properties achieved after adding these fillers depends on physicochemical properties of materials, e.g., particle shape and sizes, surface area, and surface interaction with macromolecules of polymer as well as degree of particles dispersion in the matrix. Many research works are focused on replacing conventional fillers with various layered solids, montmorillonite, hectorite, expanded graphite. The exfoliated layered structure dispersed in a nanoscale in a polymer matrix-enhanced interfacial adhesion, and thus exerts a stronger reinforcing effect. Between novel nanoscale fillers, the layered double hydroxides (LDHs) are regarded as promising materials, which are able to improve varied properties of elastomer and polymer composites [1-6]. It should be taken into account that the layered double hydroxides (LDHs) combine the unique morphology and functionality with high volume-to-surface ratio of nanofiller. As opposed to layered silicates (montmorillonites) widely used in preparing polymer nanocomposites layered double hydroxides also called hydrotalcites belong to a class of anionic minerals with general chemical structure $\left[\mathrm{M}_{1-\mathrm{x}}{ }^{\mathrm{II}} \mathrm{M}_{x}^{\mathrm{III}}(\mathrm{OH})_{2}\right]^{\mathrm{X}+}\left(\mathrm{A}^{\mathrm{n}-}\right)_{x / n} \cdot y \mathrm{H}_{2} \mathrm{O}$, where $\mathrm{M}^{\mathrm{II}}$ is a divalent metal ion; $\mathrm{Mg}^{2+}, \mathrm{Ca}^{2+}, \mathrm{Zn}^{2+}$, etc., $\mathrm{M}^{\mathrm{III}}$ represents a trivalent metal ion; $\mathrm{Al}^{3+}, \mathrm{Cr}^{3+}, \mathrm{Fe}^{3+}, \mathrm{Co}^{3+}$, etc., and $\mathrm{A}^{\mathrm{n}-}$ represents an interlayer anion, e.g., $\mathrm{Cl}^{-}$and $\mathrm{CO}_{3}{ }^{2-}[7,8]$.

The structure of hydrotalcites depends on method of synthesis, the pure LDH phase contains narrow $x$ values (a molar ratio of trivalent and divalent metal ions), $\mathrm{Al} /(\mathrm{Mg}+\mathrm{Al})$ containing in the range $0.20 \leq x \leq 0.33$. The LDH structure could be imagined by analogy to brucite, which consists hexagonal packaging of hydroxyl ions with octahedral sites filled by $\mathrm{Mg}^{2+}$ ions. In contrast to hydrotalcites, the metal hydroxide sheets in brucite are neither positive nor negative charged, the Van der Waals forces link sheets together and in consequence the distance between layers is approximately $0.48 \mathrm{~nm}$. In hydrotalcites, a part of divalent metal ions $\mathrm{M}^{\mathrm{II}}$ is substituted by $\mathrm{M}^{\mathrm{III}}$ and generates the excess of positive charge, which is neutralized by the exchangeable anions, as well as some water molecules. As a result of anions and water molecules, the presence the interlayer distance increases and is approximately $0.77 \mathrm{~nm}$ for Mg-Al-LDH $[8,9]$. Their properties such as high specific surface area $100 \pm 300 \mathrm{~m}^{2} / \mathrm{g}$, "memory effect" - an ability to reconstruct after calcination until $500^{\circ} \mathrm{C}$ the original structure by contact with solution containing anions and good anion exchange capacities resulted in increasing development of the research concerning industrial application of LDHs. Main industrial applications of LDHs are found in areas as a catalyst and a catalyst support (Ziegler-Natta, Ce02, hydrogenation, polymerization, steam reforming), adsorbent and flame retardant (wastewater, PVC stabilizer, molecular sieve), pharmacy and medicine (ion exchanger, stabilizer, drug delivery systems, molecular containers) [10]. Opposite to layered silicates, cationic clays that occur abundantly in nature, natural anionic clays, are rare (e.g., hydrotalcite $\mathrm{Mg}_{6} \mathrm{Al}_{2}(\mathrm{OH})_{16} \mathrm{CO}_{3} \cdot 4 \mathrm{H}_{2} \mathrm{O}$ [11] and mostly obtained by synthesis in the laboratory [12]. LDHs with different structures can be synthesized using various precipitation methods, among them are the most common, co-precipitation [13], and homogenous precipitation [14]. It has been reported that the solgel [15] techniques and hydrothermal reactions are also useful for synthesis of LDHs with desired composition. Table 1 summarizes brief description of the most common LDH synthesis and modification methods. 


\begin{tabular}{|c|c|c|}
\hline Synthesis methods & Brief description & Reference \\
\hline Co-precipitation & $\begin{array}{l}\text { A solution containing } \mathrm{M}^{\mathrm{II}} \text { and } \mathrm{M}^{\mathrm{III}} \text { metal } \\
\text { cations in precise concentration reacts } \\
\text { with an alkaline solution }\end{array}$ & {$[13,16-23]$} \\
\hline $\begin{array}{l}\text { Co-precipitation together with "in-situ" } \\
\text { synthesis of surfactant-modified LDH }\end{array}$ & $\begin{array}{l}\text { Co-precipitation of magnesium and } \\
\text { aluminum hydroxide layers carried } \\
\text { out in the presence of selected anions } \\
\text { resulting modified LDHs }\end{array}$ & {$[19]$} \\
\hline $\begin{array}{l}\text { Co-precipitation together with "in-situ" } \\
\text { synthesis of silane-modified LDH }\end{array}$ & $\begin{array}{l}\text { A reacting solutions containing dissolved } \\
\text { anionic surfactants and silanes, the } \\
\text { synthesis procedure allows obtain "in } \\
\text { situ" anionic surfactant-modified and } \\
\text { silane-grafted hydrotalcites }\end{array}$ & {$[18]$} \\
\hline $\begin{array}{l}\text { Homogenous precipitation, extended } \\
\text { homogenous precipitation method }\end{array}$ & $\begin{array}{l}\text { Precipitation reactions took place in the } \\
\text { presence of urea selected as ammonia } \\
\text { releasing reagent. Urea hydrolysis } \\
\text { controls the dynamic of the homogenous } \\
\text { precipitation }\end{array}$ & {$[14,19]$} \\
\hline Hydrothermal reactions & $\begin{array}{l}\mathrm{Mg}-\mathrm{Al}-\mathrm{CO}_{3}-\mathrm{HT} \text { was prepared via } \\
\text { hydrothermal synthesis using a } \\
\text { hydrothermal reaction kettle from } \\
\text { precursors' solution }\left(120^{\circ} \mathrm{C}, 16 \mathrm{~h}\right) \text { and } \\
\text { then was organic modified. }\end{array}$ & {$[24]$} \\
\hline Sol-gel techniques & $\begin{array}{l}\text { Procedure of synthesis based on } \\
\text { hydrolysis of a mixture of metal } \\
\text { alcoholates }\end{array}$ & {$[15,25]$} \\
\hline Regeneration method (memory effect) & $\begin{array}{l}\text { Rehydration of mixed oxides obtained } \\
\text { after calcination }\left(450-500^{\circ} \mathrm{C}\right) \text { of } \mathrm{LDH} \\
\text { precursor containing volatile interlayer } \\
\left.\text { anions (e.g., } \mathrm{CO}_{3}^{2-} \text { or } \mathrm{NO}_{3}^{-}\right) \text {then } \\
\text { regeneration in solution containing new } \\
\text { anions }\end{array}$ & {$[4,26-28]$} \\
\hline Ion exchange reaction & $\begin{array}{l}\text { Original LDH is dispersed in an aqueous } \\
\text { solution of the desired anionic species } \\
\text { and stirred at ambient temperature for } \\
\text { several hours }\end{array}$ & {$[17,22,23,27,29]$,} \\
\hline
\end{tabular}

Table 1. Methods of LDH synthesis.

In the case of LDHs obtained from natural sources, the easily exchangeable interlayer anion species provide opportunity of an ion exchange with different organic compounds such as carboxylates, sulfonates, and phosphates. Various reports [9, 30, 31] claim that the incorporation of organic, anionic species between LDH layers can be done by method in which the LDH is dispersed in an aqueous solution of anionic species and ion exchange occurs in room temperature during stirring the dispersion for couple of hours. The goal of modification process is to facilitate the intercalation and exfoliation of the layers; however, the effect of d-spacing increases and an interchange reaction strongly depends on the affinity of the anions, their charge, and size. In general, the purpose of organic modification is 
to enlarge the basal spacing, change the surface energy, and make particles' surface more hydrophobic by replacing of interlayer anions such as $\mathrm{Cl}^{-}, \mathrm{NO}^{3-}$, and $\mathrm{CO}_{3}{ }^{2-}$ with organic anions such as

- dodecyl sulfate DS anions [32-35]

- 1-decanesulfonate anions [4, 28]

- 1-hexadecanesulfonate [28]

- dodecylbenzenesulfonate [36, 37]

- stearate anions [38-40]

The interlayer distance after LDH organic modification is usually determined by wide-angle X-ray diffraction (XRD, WAXS). Table 2 summarizes the basal spacing of functionalized, modified LDH comparing to pristine, before modification LDHs.

\begin{tabular}{|c|c|c|c|}
\hline Intercalated anion & $\begin{array}{l}\text { Basal spacing of pristine } \\
\text { LDH }[\mathrm{nm}]\end{array}$ & $\begin{array}{l}\text { Basal spacing of modified } \\
\text { LDH [nm] }\end{array}$ & Reference \\
\hline \multirow[t]{2}{*}{ Stearate } & 0.76 & 2.75 & {$[40]$} \\
\hline & 0.90 & 3.10 & [39] \\
\hline Laurate & 0.76 & 2.45 & [26] \\
\hline \multirow[t]{2}{*}{ Decanesulfonate } & 0.76 & 2.27 & {$[4]$} \\
\hline & 0.76 & 2.23 & {$[28]$} \\
\hline Hexadecanesulfonate & 0.76 & 2.99 & {$[28]$} \\
\hline \multirow[t]{6}{*}{ Dodecylsulfate } & 0.77 & 2.56 & {$[32]$} \\
\hline & 0.76 & 2.68 & [26] \\
\hline & 0.76 & 2.76 & {$[41]$} \\
\hline & 0.76 & 2.59 & {$[34]$} \\
\hline & 0.76 & 2.77 & [35] \\
\hline & 0.76 & 2.48 & [33] \\
\hline \multirow[t]{4}{*}{ Dodecylbenzenesulfonate } & 0.76 & 2.96 & [36] \\
\hline & 0.76 & 2.95 & [26] \\
\hline & 0.77 & 2.90 & {$[42]$} \\
\hline & 0.78 & 2.80 & {$[24]$} \\
\hline $\begin{array}{l}\text { Bis (2-ethylhexyl) } \\
\text { hydrogenphosphate }\end{array}$ & 0.76 & 1.52 & {$[26]$} \\
\hline Bis (2-ethylhexyl)phosphate & 0.77 & 2.34 & {$[42]$} \\
\hline 2-Ethylhexylsulfate & 0.77 & 2.14 & [7] \\
\hline
\end{tabular}

Table 2. Basal spacing of pristine and modified LDHs. 
After modification LDHs, hybrid filler containing varied functional groups, having specific properties like light/UV/color/thermal stability can be dispersed in a nanoscale in a matrix leading to improve properties of final materials.

\subsection{Application of ionic liquids as surface functionalizing agents for layered fillers/ rubber composites}

Ionic liquids are described as salts, which are composed solely of cations and anions with melting below $100^{\circ} \mathrm{C}$. The most common organic cations are imidazolium and pyridinium derivatives or compounds based on phosphonium or tetra-alkyl ammonium cations, commonly used anions are $\left[\mathrm{BF}_{4}\right]^{-},\left[\mathrm{PF}_{6}\right]^{-},\left[\mathrm{CF}_{3} \mathrm{COO}\right]^{-}$, and $\left[\mathrm{CF}_{3} \mathrm{SO}_{3}\right]^{-}$. ILs had been used in a variety of applications including electrochemistry, chemical synthesis, and catalysis. It is possible to immobilize this type of compound onto solid supports. Ionic liquids immobilized onto solids exhibit high selectivity and activity. One of the important ILs properties is their high thermal stability comparing to conventional organic modifiers used to enhance dispersion and compatibility of nanoparticles in organic media. Treatment of different nanofillers with ILs with proper selection of constituent ions able to react with filler and improve their compatibility to polymers may open new routes for the preparation of composite materials. The adsorption of imidazolium and pyridinium ionic liquids onto layered fillers (montmorillonites) was studied. X-ray diffraction studies confirmed the intercalation of the alkyl imidazolium and pyridinium cations into the interlayer space [42-46]. Takahashi et al. [47] reported the application of ionic liquids in synthesis of anion exchangeable layered silicates. The cation exchangeable sites in the interlayer space of silicate were converted to anion exchangeable sites by a two-step reaction. The first step was the intercalation of hexadecyltrimethylammonium ions to widen the interlayer distance. The second step was immobilization of triethoxysilyl-terminated imidazolium salts with butyl or octyl group. This way obtained materials showed the affinity for $\mathrm{Cl}^{-}, \mathrm{Br}^{-}, \mathrm{I}^{-}$, and $\mathrm{NO}_{3}^{-}$but different from those of conventional anion exchangeable layered double hydroxides (LDHs). According to the literature [48], ionic liquids such as didecyldimethylammonium sachcarinate $[\mathrm{DDA}][\mathrm{Sac}]$, didecyldimethylammonium acesulfamate [DDA][Ace], benzalkonium saccharinate $[\mathrm{BA}][\mathrm{Sac}]$, and benzalkonium acesulfamate [BA][Ace] exhibited antimicrobial, antibacterial, and antifungal activities. For two of ionic liquids [DDA][Sac] and [DDA] [Ace], oral toxicity, skin irritation, and deterrent activity were also established well then to prevent harmfulness the application after immobilization on the solid surface is strongly recommended. In our previous work, we modified layered double hydroxide (LDH) and montmorillonite MMT surface with ionic liquids composed of antibacterial quaternary ammonium compounds with artificial sweetener anions saccharinate and acesulfamate, as well as derivatives of imidazolium $[9,49]$. The modified fillers were used in two matrices with different polarity: the ethylene-propylene copolymer (EPM) and hydrogenated nitrile rubber (HNBR). Elastomers were crosslinked with dicumyl peroxide (DCP). The influence of ionic liquids modification on the crosslinking density of the vulcanisates, rheometric, and mechanical properties of filled elastomers was found. The phosphonium-based ionic liquids were applied as an intercalation promoter and an antibacterial substance for the LDH-polylactic acid composites. The hydrophobic modification of LDH was conducted by 
direct ion exchange reaction with ionic liquids having phosphonium-based cation and different anions [27]. Successful anionic intercalation took place when calcined LDH reacted with a phosphinate anion containing ionic liquids in excess of the stechiometric ratio. In this way, modified LDHs could be applied as a reservoir with a controlled amount and release of phosphorous containing antibacterial substance. The ionic liquid immobilized on LDH surface minimized the plasticizing/degradative effect on polylactic PLA composites. Addition of imidazolium salts to the ionic conductivity and curing of carboxylated nitrile rubber (XNBR) were analyzed [50]. It was found that imidazolium salts containing tetrachloroaluminate ions participate in the crosslinking process of XNBR rubber. Additionally, ionic liquids showed a plasticizing effect on a rubber matrix, shifting glass temperature $\mathrm{Tg}$ to lower values with increasing ILs concentration. Other studies showed that directly incorporation of imidazolium ionic liquids into rubber mixtures increased the conductivity of XNBR and NBR vulcanizates [51].

\subsection{Preparation of rubber/LDH nanocomposites}

Many research works demonstrated that LDH anionic clay materials compounded with different elastomers significantly improve mechanical, thermal (flame retardancy), and barrier properties of polymeric materials. Various methods have been applied to obtain nanocomposites and microcomposites containing anionic clay, between them were:

- "in-situ" polymerization of previously intercalated by monomers clay [33],

- solution supported blending [32, 52],

- melt blending, diverse variants, e.g., two-step melt compounding method [4], melting directly carried out in a laboratory two-roll mill [36, 38, 39], compounding by a twin-screw extruder [53]. Table 3 summarizes diverse techniques used to obtain rubber/LDH nanocomposites.

A commonly applied method for rubber/LDH composite preparation is a two-step melt compounding procedure. First, the raw rubber is milled using two-roll mill with curing agents, then the mixture is melted at elevated temperature in an external mixer with high speed rotors, during mixing a layered filler is added [37]. A variant of the method was proposed by Costa et al. [28], first the raw rubber is melted using a temperature controlled mixer, then at elevated temperature at high-rotor speed clay is added and further mixed. Curing additives and rest of ingredients are mixed at high speed and room temperature. For easy dissolved in water or organic solvents (toluene, chloroform, THF), polymers' solution blending method provides opportunity to facilitate the intercalation of LDH because of polymer viscosity decrease. Many research studies have been devoted to develop and produce $\mathrm{LDH}$ /polymer composites with thermoplastic matrices such as polyethylene (PE), polypropylene (PP), poly(vinyl alcohol) (PVA), poly(vinyl chloride) (PVC), polystyrene (PS), poly(methyl methacrylate) (PMMA), poly(ethylene-co-vinyl acetate), poly(ethylene terephthalate) (PET) as well as epoxy resins and coatings [2, 7, 22, 27, 42, 56-58], while it has been only several reports published in the last years which referred to as properties of LDH/elastomers composites (Table 4). 


\begin{tabular}{lll}
\hline Rubber & Method of rubber/LDH compounding & Reference \\
\hline Polychloroprene CR & $\begin{array}{l}\text { Melt compounding in laboratory size } \\
\text { open two-roll mixing mill }\end{array}$ & {$[36]$} \\
Nitrile butadiene rubber NBR & $\begin{array}{l}\text { Melt compounding in laboratory size } \\
\text { open two-roll mixing mill }\end{array}$ & {$[38]$} \\
Hydrogenated nitrile rubber HNBR & Melt compounding in laboratory size & {$[54]$} \\
open two-roll mixing mill & \\
Carboxylated nitrile rubber XNBR & Internal mixer with temperature and & {$[8,55]$} \\
Ethylene propylene diene rubber EPDM & rotors speed control & \\
Ethylene propylene diene rubber EPDM & Melt compounding using twin-screw & {$[53]$} \\
Nitrile butadiene rubber NBR & Two-step melt compounding method & {$[4]$} \\
Carboxylated nitrile rubber XNBR & Two-step melt compounding method & {$[51]$} \\
Carboxylated nitrile rubber XNBR & Two-step melt compounding method & {$[4]$} \\
Carboxylated nitrile rubber XNBR & Two-step melt compounding method & {$[37]$} \\
Ethylene propylene diene rubber EPDM & Two-step melt compounding method & {$[28]$} \\
Polyurethane/nitrile rubber blends & Solution blending in toluene & {$[32,52]$} \\
Silicon rubber SR & Solution blending in THF & {$[34]$} \\
Polyurethane & Solution blending in CCl & {$[35]$} \\
\hline
\end{tabular}

Table 3. Methods of rubber/LDH composites preparation.

\begin{tabular}{|c|c|c|c|c|}
\hline Type of rubber & LDH loadings & $\begin{array}{l}\text { Improvement of rubber } \\
\text { properties }\end{array}$ & Structure of composite & Reference \\
\hline PUR/NBR blends & $1,3,5,8 w t \%$ & $\begin{array}{l}\text { Mechanical, thermal } \\
\text { properties, flame } \\
\text { retardancy, solvent } \\
\text { resistance }\end{array}$ & partially exfoliated & [34] \\
\hline PUR & $1,3,5,8 \mathrm{wt} \%$ & $\begin{array}{l}\text { Mechanical, adhesive } \\
\text { properties, thermal } \\
\text { stability }\end{array}$ & partially exfoliated & [59] \\
\hline PUR & $0.5,1,2,5 \mathrm{wt} \%$ & $\begin{array}{l}\text { Mechanical properties, } \\
\text { gases permeability }\end{array}$ & $\begin{array}{l}\text { exfoliated }<2 \mathrm{wt} \% \mathrm{LDH}, \\
\text { intercalated }>2 \mathrm{wt} \% \mathrm{LDH}\end{array}$ & [33] \\
\hline EPDM & $0,5,7.5,10 \mathrm{phr}$ & Thermal stability & Not exfoliated & [4] \\
\hline EPDM & $0,2,3,4,8 w t \%$ & $\begin{array}{l}\text { Mechanical properties, } \\
\text { thermal stability }\end{array}$ & Partially exfoliated & {$[32,52]$} \\
\hline CR & $5 \mathrm{phr}$ & $\begin{array}{l}\text { Mechanical properties, } \\
\text { thermal stability, } \\
\text { improvement of } \\
\text { compression set properties, }\end{array}$ & Partially intercalated & {$[36]$} \\
\hline
\end{tabular}




\begin{tabular}{|c|c|c|c|c|}
\hline Type of rubber & LDH loadings & $\begin{array}{l}\text { Improvement of rubber } \\
\text { properties }\end{array}$ & Structure of composite & Reference \\
\hline SiR & $1,3,5,8 w t \%$ & $\begin{array}{l}\text { Mechanical properties, } \\
\text { thermal stability, solvent } \\
\text { resistance }\end{array}$ & Exfoliated & [35] \\
\hline XNBR & $5,7.5,10 \mathrm{phr}$ & $\begin{array}{l}\text { Significant improvement } \\
\text { in mechanical properties } \\
\text { because of polar/ionic } \\
\text { interaction }\end{array}$ & Exfoliated & {$[4]$} \\
\hline XNBR & $5,7.5,10 \mathrm{phr}$ & $\begin{array}{l}\text { Improvement in } \\
\text { mechanical properties, } \\
\text { influence on the strain- } \\
\text { induced crystallization } \\
\text { process }\end{array}$ & $\begin{array}{l}\text { Exfoliated, partially } \\
\text { exfoliated }\end{array}$ & {$[28]$} \\
\hline XNBR & $2.5,5,10,20,30 \mathrm{phr}$ & $\begin{array}{l}\text { Improvement in the tensile } \\
\text { strength, air permeability, } \\
\text { enhanced UV stability }\end{array}$ & Not studied & [55] \\
\hline XNBR & $\begin{array}{l}30 \text { phr, various } \\
\text { ionic liquids 5, 10, } \\
15 \text { phr }\end{array}$ & $\begin{array}{l}\text { Increased conductivity } \\
\text { (result of ILs addition) }\end{array}$ & Not studied & {$[52,53]$} \\
\hline XNBR & $10,20,30,40 \mathrm{phr}$ & Mechanical properties & Not studied & [8] \\
\hline XNBR & $2.5,5,10,20,30 \mathrm{phr}$ & $\begin{array}{l}\text { Mechanical, barrier } \\
\text { properties, cure degree, }\end{array}$ & Not studied & {$[60]$} \\
\hline
\end{tabular}

Table 4. Properties of LDH/rubber composites according to various authors' studies.

\subsection{Application of LDHs as a part of curing system and reinforcing filler for various rubbers}

This section discusses the effectiveness of LDHs in various elastomeric systems. Currently, the possibilities of LDH application both as a curing substances and reinforcing filler in elastomer composite synthesis seem particularly interesting and have attracted research and industrial interest. Emphasis has been given to use $\mathrm{LDH}$ as $\mathrm{ZnO}$ substitute during rubber mixture compounding, which could lead to decrease in zinc oxide amount used in rubber crosslinking and offer the environmentally friendly rubber products. In sulfur vulcanization, the mixture of stearic acid with zinc oxide is used. According to European Union regulation, the use of zinc oxide in rubber compounds should be restricted because of its toxicity to aquatic species. Compounds containing zinc in form such as zinc stearate, zinc-2-ethylhexanoate, and zinc borate were studied as a possible substitute of zinc oxide $(\mathrm{ZnO})$ for sulfur crosslinking of SBR and EPDM rubbers. Applied substances characterized the differences in crosslinking activity related to the stability of the zinc complexes [61]. It was found that zinc-stearate-modified LDH could be applied as a part of NR and NBR rubber crosslinking system able to cure elastomer in shorter time. Recently, Das et al. [38] designed and applied LDH mineral filler in rubber formulation preparing environmental friendly rubber composites. Stearic acid and zinc are essential activators in sulfur vulcanization to promote 
crosslinking of rubber chains. Synthesized zinc-stearate-modified LDH was a source of both zinc and stearate ions, and it served as a triple multifunctional additive: (1) accelerator able to deliver zinc ions in the vulcanization reactions, (2) activator delivering stearate ions, (3) acting as highly anisotropic nanofillers able to reinforce a rubber matrix. Additionally, nitrile rubber NBR vulcanizates crosslinked by sulfur and modified LDH zinc oxide in the absence of $\mathrm{ZnO}$ and stearic acid were transparent (showing a high degree of optical transparency) what was not possible to obtain in the case of traditional $\mathrm{ZnO}$, sulfur, and stearic acid curing system. WAXS and TEM studies confirmed intercalation and exfoliation of LDHs particles in rubber but the rubber matrix still contained ordered structures to some extent. The important advantage of this approach is the reduction of components added during rubber mixture processing as well as decrease in necessary $\mathrm{ZnO}$ content what has potentially great importance for the rubber industry.

Another possibility of LDH application is its activity as a coagent in peroxide crosslinking. The activity of hydrotalcite as coagents in the crosslinking of hydrogenated acrylonitrile-butadiene rubber was studied [54]. The layered material was surface modified with unsaturated itaconic acid. Application of layered material LDH together with itaconic acid increased the efficiency of dicumyl peroxide DCP crosslinking without scorching. Owing to the presence of unsaturated bonds, $\mathrm{LDH} /$ itaconic acid coagents reacted with peroxide or polymer radicals and as a consequence it was grafted to the polymer chains. The decrease of the optimal vulcanization time and improved crosslink density as well as tensile strength was observed. The formation of additional ionic crosslinks in the elastomer network was concluded. It was found that multifunctional ionic clusters showed ability to slip on the surface of the solid LDH coagent particles resulted in a high ability of vulcanisates for stress relaxation. Modified LDHs allow the replacement of traditional coagents, zinc salts. Layered double hydroxides and modified multifunctional LDHs have been applied not only to natural and nitrile rubbers but also elastomers with different polarity and chemical structure [62]. Polar particles such as LDH solids are badly dispersible in the nonpolar EPDM. This elastomer due to unsaturated bonds present in structure offers possibility of sulfur vulcanization. The presence of a saturated backbone causes a substantial anti-aging property comparing to other rubbers. The improvement of LDHs dispersion in nonpolar matrices has been of increasing research interest [4, 32, 52, 53]. Pradhan et al. [4] studied Zn-Al LDHs potential as a reinforcing filler in ethylene-propylene diene terpolymer (EPDM). Their studies showed that conventional melt compounding of EPDM with unmodified LDHs is not causing the exfoliation of LDHs layers. Analysis of WAXS patterns confirmed that there is no intercalation of the modified LDH by elastomer chains. Some improvement of mechanical properties was observed with the increase of LDH loadings. The influence of LDH on the curing behavior (higher curing level, faster curing time) of EPDM was observed for higher amount ( $\geq 10$ parts per hundred rubber, phr) of $\mathrm{Zn}-\mathrm{Al} \mathrm{LDH}$ comparing to EPDM mixtures containing $4 \mathrm{phr}$ of $\mathrm{ZnO}$. The effect on the curing level, higher crosslinking state was confirmed by DSC study, the glass transition temperature $T_{\mathrm{g}}$ of EPDM/Zn-Al-LDH composites shifted to higher values. The XRD patterns and TEM micrographs confirmed that the application of solution intercalation method instead of conventional melt compounding for LDH/EPDM composites led to exfoliation of the dodecylsulfate-modified Mg-Al LDH in EPDM rubber caused improving of mechanical 
properties for $2-8 \mathrm{wt} \%$ clay loadings $[32,52]$. The effect of Mg-Al-LDH addition on the EPDM photo-oxidation stability was reported by Kumar et al. [53]. The photostabilizing efficiency of LDH on EPDM was monitored after accelerated UV irradiation at $60^{\circ} \mathrm{C}$ for different time intervals by the measurement of the carbonyl and hydroxyl group changes using FTIR spectroscopy. For the samples containing LDH, it was confirmed that the presence of filler enhanced the degradation of EPDM. EPDM/LDH composites showed higher degradation rate than pristine EPDM. The photodegradation of filled rubber was studied under acidic conditions, the samples before accelerated aging were kept in vapor phase containing $5 \%$ nitric acid concentration for $3 \mathrm{~h}$. Acidic-treated EPDM/LDH showed almost equal degradation as under isolated conditions. The results underlined the advantages of LDHs as an acid killer. Wang et al. [63] prepared a high performance elastomeric flame retardant nanocomposite based on maleic anhydride grafted ethylene-propylene-diene terpolymer MA-EPDM and synthesized organic-modified LDH. Dodecyl benzene sulfonate-modified LDH was applied as a separate filler (40 phr) and in the presence of flame retardant FR composed pentaerythritol, ammonium polyphosphate, and methyl cyanoacetate ( $2 \mathrm{phr}$ LDH/38 phr FR). The rubber compounds were prepared using a melt compounding method by a two-roll mixing mill. SAXS and TEM studies confirmed an exfoliated structure of LDH in composite containing 2 phr LDH and 38 phr FR. The introduction of a small amount of LDH to the flame retardant MA-EPDM led to the significant decrease in the heat release rate, mass loss, fire growth rate of the nanocomposite measured by microscale combustion colorimeter and cone calorimeter test. The addition of LDH did not affect the mechanical properties of MA-EPDM.

The effect of two opposite nanoclays, montmorillonite MMT and layered double hydroxide LDH on the properties of chloroprene rubber was discussed [36]. Das et al. [36] reported that both filler improved mechanical properties of CR rubber, though reinforcing effect was stronger for organic-modified OMMT. Dynamic mechanical analysis (DMA) confirmed stronger MMT tendency to induce the crystallization of CR rubber comparing to $\mathrm{LDH}$, which resisted crystallization. OMMT restricted the mobility of elastomer chains stronger than $\mathrm{LDH}$ resulting in the reduced height of $\operatorname{tg} \delta$ peak. Storage modulus data obtained for organic-modified MMT and LDH-filled CR samples at room showed a significant increase of this parameter for OMMT/CR than for OLDH/CR which indicated stronger reinforcing nature of MMT. Additionally, a decrease in the value of storage modulus at higher temperature $\left(35-45^{\circ} \mathrm{C}\right)$ in the case OMMT/CR composites was observed, this effect was attributed to the melting of the polychloroprene crystal domain and did not occurred for LDH-CR composites. Authors suggested that reduced crystallization and restricting effect of OLDH addition on crystals domain formation might be due to the presence of different heterogeneous microstructure on the LDH and MMT surface, which prevents immobilizing and ordering of elastomer chains.

Using a solution styrene-butadiene elastomer SSBR smart, thermotropic materials based on Zn-Al-LDH filler were obtained [64]. Thermotropic materials are defined as materials able to change reversibly from being transparent to a milky white (refractive) state as a function of temperature. Material was fabricated using sulfur-cured solutions of styrene-butadiene rubber (SSBR) containing up to 100 parts per hundred rubber (phr) of incorporated Zn-Al-LDH. 
Zn-Al-LDH/SSBR composite becomes opaque when heated and restores the transparency after cooling to room temperature. This behavior was reversible and the material showed a gradual change in transparent/opaque characteristics upon heating, without showing any critical transition temperature. Effect was found to be increased as the amount of LDH was increased indicating that the amount of LDH loaded inside elastomer matrix qualitatively controls the thermotropic properties of the material. The addition of LDH gradually improved the mechanical, dynamic mechanical performance and thermal stability of the base elastomer.

Pradhan et al. [35] investigated dodecylsulfonate-modified LDH as a promising filler for the preparation of inorganic elastomer composites based on silicone rubber. Organic DS-LDHp/ silicon rubber composites with significant degree of exfoliation were prepared by the solution intercalation in $\mathrm{CCl}_{4}$ method. A vinyl-terminated, linear polydimethylsiloxane polymer, and the crosslinking agent as a polysiloxane containing silicone-bonded hydrogen atoms were base materials for nanocomposite preparation with different filler loadings. A platinum-catalyzed hydrosilylation reaction forming the crosslinked silicone rubber SR. The results of X-ray diffraction and transmission electron microscopy analysis demonstrated the formation of exfoliated structures of organo-modified LDH layers in the SR matrix. The interactions between Si-O polar functionality and -OH group of DS-LDH caused improvement of mechanical properties, especially the tensile strength. Thermogravimetric analysis indicated that the thermal degradation temperature (at $50 \%$ weight loss) of the exfoliated SR/DS-LDH $(1 \mathrm{wt} \%)$ nanocomposites was higher than that of pure SR [35].

A similar solution intercalation method was used for the fabrication of a stearate-modified layered double hydroxide silicone rubber (ST-LDH/SR) composites [65]. The characterization of the material confirmed the formation of a predominantly exfoliated dispersion of St-LDH layers of 75-100 $\mathrm{nm}$ in width and about 1-2 $\mathrm{nm}$ in thickness. As it took place for the DS-LDH/SR composites, thermogravimetric analysis indicated the improvement in thermal properties of final materials, thermal degradation temperature of the exfoliated ST-LDH/SR $(1 \mathrm{wt} \%)$ was about $80^{\circ} \mathrm{C}$ higher than that of pristine SR. After the addition of ST-LDH, a significant improvement in tensile strength and storage modulus was attained. A reduction of oxygen permeability was observed for ST-LDH/SR containing $3 \mathrm{wt} \%$ of layered filler [65].

\subsection{Ionic elastomers based on carboxylated nitrile rubber (XNBR)}

Ionomers (ionic elastomers) belong to a group of polymers containing a low amount of ionic functional groups (e.g., $\mathrm{COO}^{-}$, or $\mathrm{SO}_{3}{ }^{2-}$ ). The presence of ionic functionality in the hydrocarbon backbone provides special properties, ability to form hierarchal microstructure of ionic clusters. Carboxylated acrylonitrile rubber (XNBR) has excellent abrasion resistance and chemical resistance (especially to aliphatic hydrocarbons) as compared to other elastomers. XNBR is a terpolymer of acrylonitrile, butadiene, and monomers containing carboxyl groups, such as acrylic and metacrylic acids. The presence of carboxyl groups provides additional curing sites and allows to form ionic clusters. 
It was reported for ionic elastomers that two principal types of ionomer salts such as multiplets and clusters are formed [66]:

1. Small aggregates with a low number of ion pairs (approx. 6-8), this type of cluster act a similar way as physical crosslinks. The structure of ionic aggregate depends on the size of ion pair in multiplet as well as is limited by steric effects of the polymer chain segments surrounding the ion functional groups. The multiplets are statistically dispersed in a hydrocarbon matrix and do not form any separate phase.

2. Large aggregates, clusters, the ordered ionic structure containing a higher amount of ion pairs as well as nonionic hydrocarbon content. Clusters behave as a separate phase, showing special relaxation behavior at high temperature and acting not only as physical crosslinks but also as a reinforcing filler. Therefore, the properties of ionic elastomers are enhanced as compared with those containing only conventional crosslinks.

The crosslinking reaction and its kinetic depend on the type of crosslinked substance used. Different functional sites present in carboxylated nitrile rubber, unsaturated bonds, nitrile groups $(-\mathrm{CN})$, and carboxylic groups $(-\mathrm{COOH})$ provide an opportunity of the formation of covalent, ionic, and physical crosslinks. The functional - $\mathrm{COOH}$ groups of XNBR rubber cause the reaction with many compounds that may occur allowing the formation of carboxylic salts. Among them, zinc oxide remains the most popular substance used as an XNBR ionic activator.

Ibarra et al. [67-69] examined various XNBR crosslinking agents, the studies compared conventional sulfur/accelerator systems from which $\mathrm{ZnO}$ was excluded and peroxide system with magnesium oxide, zinc peroxide system Struktol ZP 1014 (50 wt \% ZnO and $\mathrm{ZnO}_{2^{\prime}}$ $30 \mathrm{wt} \%$ inorganic dispersing agent, $20 \mathrm{wt} \%$ organic dispersing agent) and anhydrous copper sulfate (II). Significant differences were found in vulcanization rheometric curves for applied curing agents. The different viscous component curves $S^{\prime \prime}(\mathrm{dNm})$ with a time-indicated type of bonds obtained for each crosslinking agent. The descendant curve was observed from the start of the reaction. During the formation of ionic bonds $(\mathrm{MgO})$, the curve increased until it reached a plateau [67]. The formation of two types crosslinks ionic and covalent $(\mathrm{ZnO})$ or ionic and coordination $\left(\mathrm{CuSO}_{4}\right)$ entailed changed in curve shapes, graphs showed a maximum followed by a decrease in normalized viscous component value $S^{\prime}$. The presence of ionic associations influenced rubber properties increasing stress at $100 \%, 300 \%$ strain, tensile, and tear strength, Shore A hardness, and compression set and room temperature [67]. The crosslinking of XNBR with magnesium oxide led to obtain an ionic elastomer with thermoplastic nature [70]. Ionic associations were thermally labile and formed a segregated microphase showing a relaxation at high temperatures called ionic transition. Ionic elastomers XNBR crosslinked with magnesium oxide and filled with organic-modified layered montmorillonite (OMMT) have been prepared [71]. Vulcanization parameters and rheological properties of $\mathrm{MgO}$ cured XNBR were affected depending on a filler type. The glass transition temperature and ionic transition temperature were shifted in comparison with unfilled $\mathrm{MgO}$ cured XNBR which suggested that the addition of OMMT influenced the 
formation of ionic clusters during crosslinking. The XNBR rubber was crosslinked through ionic bonds with calcium oxide $\mathrm{CaO}$ [72]. Two reaction temperatures 100 and $150^{\circ} \mathrm{C}$ have been studied. The changes in curing behavior, reduction in the reaction time, and mechanical properties corresponded with the rise in temperature and were directly proportional to the $\mathrm{CaO}$ amount used.

As it takes place for zinc, magnesium, and calcium oxides, the layered double hydroxides are able to participate in crosslinking of carboxylated nitrile rubber XNBR. LDHs as a filler for ionic elastomers can act as:

(a) reinforcing additives dispersed in intercalated or exfoliated state,

(b) activators promoting sulfur crosslinking replacing traditionally used zinc oxide,

(c) substance providing metal cations for metal-carboxylate crosslinking.

Additionally, the basic hydroxyl groups present on LDHs' surfaces enhance their potential to form filler/filler interactions and this way strengthen the reinforcing effect. It was observed that for the polar functionalized elastomer XNBR containing carboxylic groups in the presence of LDHs, the secondary interactions between surface of the filler and elastomer matrix occurred [4]. For XNBR/LDHs composites, strong and stable filler/polymer interface is formed and tensile failure and fracture do not take place through the interface but rather through a matrix. Another important aspect is that LDHs can influence the strain-induced crystallization of XNBR rubber [4, 28]. Pradhan's research group studies showed that Mg-Al-LDHs can significantly improve the mechanical properties of XNBR rubber as a result of strong interfacial interactions between filler and elastomer chains [4]. Storage modulus of LDH/XNBR composites measured using dynamic mechanical analysis increased with increasing LDH loading, on the other hand, tano maximum values decreased with increasing filler concentration, confirming the strong interactions at the filler/rubber interface. The ability of LDHs to interact with XNBR has been proven by FTIR analysis [28] and FTIR-ATR analysis [55, 60] with increasing content of LDH the intensity of the band corresponding to - $\mathrm{COOH}$ decreased remarkably. The Mg-Al-LDH filler may provide metal ions for reaction with the $-\mathrm{COOH}$, thereby leading to the formation of ionic clusters. The effect of various LDHs' structures on the curing behavior was investigated $[8,9,60,73]$. The $\mathrm{Mg} / \mathrm{Al}$ ratio strongly affected the crosslink density of Mg-Al-LDH/XNBR composites resulted in mechanic-dynamical and barrier properties of vulcanizates [55,60].

The next section will discuss the influence of different Mg-Al-LDH structures (Mg/Al ratio, surface area, particles sizes) on the curing behavior, mechanical, thermal, and barrier properties of nitrile rubber. It is well known that the modification with organic compounds containing an anionic end group and long hydrophobic chains leads to better filler dispersion in polymeric materials as a result of it, a decrease in surface energy and increase in the thermodynamic compatibility with polymer as compared with materials containing unmodified LDH. The study will be focused on the possibility of LDHs' modification using different ionic liquids to improve the properties nitrile rubbers composites, NBR, HNBR, and XNBR. 


\section{Materials and characterization}

\subsection{Preparation of ionic liquid-modified LDH fillers}

The ionic liquids such as didecyldimethylammonium saccharinate [DDA][Sac], didecyldimethylammonium acesulfamate [DDA][Ace], benzalkonium saccharinate [BA][Sac], and benzalkonium acesulfamate [BA][Ace] were synthesized using a procedure described by Hough-Troutman et al. [48]. Hydrotalcite HT with 14.1/4.5/42.2/39.2 atomic\% $\mathrm{Mg} / \mathrm{Al} / \mathrm{O} / \mathrm{C}$ ratio (indicated using XPS analysis) supplied by Sigma-Aldrich after calcination at $490^{\circ} \mathrm{C}$ for $3 \mathrm{~h}$ was dispersed in the solution of a modifying agent containing $10 \mathrm{wt} \%$ excess of ionic liquid comparing to stoichiometric ratio. The dispersion was mixed for $30 \mathrm{~min}$ using ultrasonic bath with a frequency of $35 \mathrm{kHz}$. Then, the mixture was stirred for the following $24 \mathrm{~h}$, and the solvent was evaporated using a vacuum evaporator at $50^{\circ} \mathrm{C}$. Surface modified LDHs were dried in a vacuum drier at $60^{\circ} \mathrm{C}$ for $48 \mathrm{~h}$.

\section{2. $\mathrm{LDH}$ properties analysis}

\subsubsection{Aggregates size analysis}

The size of the metal oxides and LDHs was determined using a Zetasizer Nano Serie S90 (Malvern Instrument). The size of particles in a water dispersion was measured based on the dynamic light scattering (DLS) method. The concentration of the dispersion was $0.2 \mathrm{~g} / \mathrm{dm}^{3}$. Additionally, the size of LDH agglomerates in paraffin oil (model of elastomer matrix) was determined to estimate the tendency of LDH agglomeration in a nonpolar medium. Before the measurement, dispersions were stabilized using ultrasonic treatment (Bandelin Sonorex DT 255).

\subsubsection{Surface area measurement}

The specific surface area was measured based on nitrogen adsorption using a Gemini 2360 V2.01 porosimeter (Micrometrics, USA). The samples were degassed for $20 \mathrm{~h}$ at $120^{\circ} \mathrm{C}$ under vacuum. Measurements were performed according to the Brunauer-Emmett-Teller (BET) nitrogen adsorption method, full adsorption isotherms were collected.

\subsubsection{Oil absorption measurement}

The oil absorption parameter OAN of layered double hydroxides (LDHs) was measured according to ASTM D2414 using Absorptometer C equipment connected with Brabender station. The process parameters were sample weight $20 \mathrm{~g}$, titration rate $4.0 \mathrm{ml} / \mathrm{min}$. The oil used in this study was dibutyl phthalate (DBP).

\subsubsection{X-ray diffraction analysis (XRD)}

Room-temperature powder X-ray diffraction patterns were collected using a DRON 2EJ apparatus with $(\mathrm{CuK} \alpha)$ radiation. Data were collected in the $2 \theta$ range of $1-21^{\circ}$ with $0.05^{\circ}$ step 
and $5 \mathrm{~s}$ exposition per step. The d-spacing within clay galleries was calculated according to Bragg equation $(n \lambda=2 d \sin \theta)$.

\subsubsection{Analysis of filler particles morphology}

The morphology of filler particles was evaluated by scanning electron microscopy (SEM) using an LEO 1530 Gemini equipment (Zeiss/Leo, Germany). Samples with a graphite-coated structure were used in these investigations.

\subsubsection{Thermogravimetric analysis}

The thermal decomposition of layered double hydroxides was performed using TGA/DSC1 (Mettler Toledo) analyzer. Samples were heating from 25 to $800^{\circ} \mathrm{C}$ in an argon atmosphere with the heating rate of $10^{\circ} \mathrm{C} / \mathrm{min}$.

\subsection{Preparation of rubber mixtures}

The rubber-layered double hydroxide composites were prepared using:

- hydrogenated acrylonitrile-butadiene rubber HNBR (Therban 3407, Mooney viscosity ML $(1+4) 100^{\circ} \mathrm{C} 70 \pm 7 \mathrm{MU}-$ ISO 289/ASTM D 1646, specific gravity 0.95 , total ash $\leq 0.49 \mathrm{wt} . \%-$ ISO 247/ASTM D 5668) containing $34 \pm 1.0 \mathrm{wt} \%$ acrylonitrile (ISO $24698-1$ ) and $\leq 0.9 \%$ of residual double bonds (FTIR spectroscopy) after hydrogenation was obtained from Arlanxeo. It was crosslinked with dicumyl peroxide DCP (Sigma-Aldrich).

- Carboxylated acrylonitrile-butadiene rubber XNBR (Krynac X750, Mooney viscosity ML $(1+4) 100^{\circ} \mathrm{C} \mathrm{MU}-47 \pm 5 \mathrm{MU}-$ ISO $289 / \mathrm{ASTM} \mathrm{D}$ 1646, specific gravity 0.99 , total ash $\leq 1.0$ wt. $\%$-ISO 247/ASTM D 5668) containing $27 \pm 1.5 \mathrm{wt} \%$ acrylonitrile (ISO 24698-1) and $\leq 7 \%$ of carboxylic group - $\mathrm{COOH}$ (FTIR spectroscopy) was obtained from Arlanxeo. Elastomer was crosslinked using nanometric $\mathrm{ZnO}$ and $\mathrm{MgO}$ (Sigma-Aldrich).

Various layered double hydroxides were applied as fillers as well as curing substances. Among them were magnesium aluminum layered double hydroxides $\mathrm{Mg}-\mathrm{Al}-\mathrm{CO}_{3}-$ LDHs Pural ${ }^{\circledR}$ MG $30 \mathrm{HT}, 63 \mathrm{HT}, 70 \mathrm{HT}$ with different $\mathrm{MgO} / \mathrm{Al}_{2} \mathrm{O}_{3}$ ratio, products of Sasol Germany GmbH (thereafter designated as LDH30, LDH63, LDH70). These materials were used without modification as curing substances for XNBR rubber at different filler loadings. The composites contained 10, 20, $30 \mathrm{phr}$ (parts per hundred rubber). The LDHs/XNBR rubber mixtures were prepared using a melt compounding method. The rubber and filler were homogenized using Brabender Measuring Mixer N50. The rubber compounds were processed using $50 \mathrm{rpm}$ (revolutions per minute) rotors speed at the initial temperature $60^{\circ} \mathrm{C}$. After $5 \mathrm{~min}$ of rubber mastication $\mathrm{LDH}$ was added and mixed for $15 \mathrm{~min}$.

Synthetic hydrotalcite HT (Sigma-Aldrich) was used to prepare HNBR composites cured with dicumyl peroxide (DCP) and after modification with various ionic liquids, IL-HT was applied as an interface strengthening functional filler for HNBR rubber. The ionic liquid-modified HT was used as a reinforcing filler for metal oxide cured carboxylated nitrile rubber XNBR as 
well. HT/HNBR and HT/XNBR rubber compounds with the formulation given below were prepared using a laboratory two-roll mill in the temperature about $40^{\circ} \mathrm{C}$.

- HNBR 100 phr, DCP 3 phr, various HT loadings, IL-HT 10 phr

- XNBR 100 phr, ZnO 3 phr, IL-HT 10 phr.

Additionally, two-step melt compounding method was applied for HNBR rubber composites. First, hydrotalcite HT was grinded with $10 \mathrm{wt} \%$ of various ionic liquids till homogenous paste was obtained. The rubber compounds were processed in an internal mixer Brabender $\mathrm{N} 50$ at $50 \mathrm{rpm}$ speed and $50^{\circ} \mathrm{C}$ initial temperature. After $5 \mathrm{~min}$ of rubber mastication, the IL/ HT paste was added and homogenized during $15 \mathrm{~min}$. Subsequently, the compounded rubbers were homogenized with a curing system in a laboratory two-roll mill (temperature $40^{\circ} \mathrm{C}$, friction ratio 1:1.2, dimension of rolls-diameter $200 \mathrm{~mm}$, length $450 \mathrm{~mm}$ ).

\subsection{Characterization techniques}

\subsubsection{Vulcanization studies}

The curing characteristics of the LDH/rubber composites were determined using MonTech RPA 3000 dynamic rheometer, a sinusoidal strain of 0.5 and $7 \%$ was applied at a frequency of $1.67 \mathrm{~Hz}$. The curing curves were studied at different temperatures. The optimum cure time $\left(t_{90}\right)$, scorch time $\left(t_{\Delta 2}\right)$, minimum torque $\left(S_{L}^{\prime}\right)$, maximum torque $\left(S_{H}^{\prime}\right)$, and delta torque $\left(\Delta S^{\prime}=S_{H}^{\prime}-S_{L}^{\prime}\right)$ were calculated. The rheometric studies were done according to ISO 13145, ISO 6502, ASTM D5289, and ASTM D6204 standards.

\subsubsection{Crosslink density}

The crosslink density $\left(v_{t}\right)$ was calculated from measurement of equilibrium swelling in toluene for $48 \mathrm{~h}$ at $25^{\circ} \mathrm{C}$ using the Flory-Rehner equation [74].

$$
v_{t}=\frac{\ln \left(1-V_{p}\right)+V_{p}+\chi \cdot V_{p}^{2}}{V_{s}\left(V_{p}-\frac{V_{p}}{2}\right)}
$$

where $v_{t}$ is crosslink density, $V_{\mathrm{p}}$ is the volume fraction of elastomer in the swollen gel, and $V_{\mathrm{s}}$ is the molar volume of solvent $\left(\mathrm{mol} / \mathrm{cm}^{3}\right)$.

The Huggins parameters of the elastomer-solvent interaction $\chi$ were calculated for XNBR and HNBR rubber from the equations:

- $\chi=0.501+0.273 V_{\mathrm{r}}(\mathrm{HNBR})[54]$

- $\chi=0.487+0.228 V_{\mathrm{r}}(\mathrm{XNBR})[75]$,

where $V_{\mathrm{r}}$ is the volume fraction of elastomer in the swollen gel.

The amount of ionic crosslinks in the elastomer network was determined from the equilibrium swelling in toluene placed in a desiccator with saturated ammonia vapor ( $25 \%$ aqueous solution). 
The content of ionic crosslinks $\Delta v[76]$ was calculated according to equation:

$$
\Delta v=\frac{v_{t}-v_{a}}{v_{t}} \times 100 \%
$$

where $v_{a}$ is the crosslink density determined for samples treated with ammonia vapor.

\subsubsection{Stress-strain behavior}

Tensile properties were characterized on a Zwick1435 tensile testing machine. The moduli at 100,200 , and $300 \%$ elongation, tensile strength, and elongation at break were measured at $25^{\circ} \mathrm{C}$ with crosshead speed of $500 \mathrm{~mm} / \mathrm{min}$ for testing type 2 dumb-bell specimens prepared according to the ISO-37-2005 standard. Five different specimens were tested and the average value for each formulation was reported.

\subsubsection{Thermogravimetric analysis (TGA) and DSC analysis}

Thermal decomposition of the rubber compounds was performed using TGA/DSC1 Metler Toledo equipment. Samples were analyzed in the presence of air from 25 to $800^{\circ} \mathrm{C}$ using a heating rate of $10^{\circ} \mathrm{C} / \mathrm{min}$.

\subsubsection{Analysis of filler dispersion}

The LDH dispersion in the elastomer matrix was evaluated by scanning electron microscopy (SEM) (Leo153 Gemini). The rubber composites were broken down in liquid nitrogen and the fracture surface of the material was examined. Prior to analysis, the samples were coated with graphite.

\subsubsection{Aging studies}

Accelerated aging studies under different conditions were carried out. After aging, stressstrain tests were performed. The aging coefficients $\left(K_{\text {type of aging }}\right)$ were calculated according to the equation:

$$
K=\frac{(T S \cdot E B) \text { after aging }}{(T S \cdot E B) \text { before aging }}
$$

where TS is tensile strength (MPa) and EB is elongation at break (\%). In addition, the changes in crosslink density were estimated by the swelling method using toluene as a solvent as described above.

The conditions of UV aging studies were as follows: $120 \mathrm{~h}$ during which alternating day (radiation intensity $0.7 \mathrm{~W} / \mathrm{m}^{2}$, temperature $60^{\circ} \mathrm{C}$, duration $8 \mathrm{~h}$ ) and night segments (without $\mathrm{UV}$ radiation, temperature $50^{\circ} \mathrm{C}$, duration $4 \mathrm{~h}$ ) were repeated.

Weathering aging studies were carried out using Atlas Weather Ometer Ci 4000 equipment, in $100 \mathrm{~h}$ using selected day and night panels with parameters such as: day panel: time $240 \mathrm{~min}$, energy of radiation $0.7 \mathrm{~W} / \mathrm{m}^{2}$, humidity $60 \%$, night panel: time $120 \mathrm{~min}$, humidity $50 \%$. 


\section{Results and discussion}

\subsection{Characterization of LDHs}

It is well known that the particle size and the distribution of the filler aggregates in the elastomer matrix can be the key factors to achieve the significant improvement of mechanical properties. An uneven dispersion and the occurrence of single larger agglomerates acted as the "weak center" initiating breaking during deformation lead to deterioration of the material properties. Moreover, reduction of aggregates size and increase the specific surface area resulting in enhancement of the interphase contact between the solid surface and elastomers and thus has strong impact on the reinforcing effect. Therefore, the aggregates size in water and paraffin oil for various $\mathrm{Mg} / \mathrm{Al}$ ratio layered double hydroxides was studied (Table 5).

Layered double hydroxides, LDH-30 and LDH-70, characterized a strong tendency to agglomerate due to electrostatic interactions and hydrogen bonds between the layers and as a result formed aggregates in range larger than $2 \mu \mathrm{m}$ in water and larger than $4 \mu \mathrm{m}$ in nonpolar medium paraffin oil. Size of the main fraction by a number increased with the increasing ratio of $\mathrm{Mg} / \mathrm{Al}$. The $\mathrm{LDH}$ with the lowest $\mathrm{Mg} / \mathrm{Al}$ ratio $\mathrm{LDH}-30$ characterized the highest value of surface area after activation $3 \mathrm{~h}$ in $550^{\circ} \mathrm{C}$ what is an advantage considering its application as potentially reinforcing filler but unfortunately it also showed strong tendency to agglomeration. One of the filler characteristic contributed to reinforcing effect is the tendency to create "own structure" in an elastomer matrix as a result of filler/filler interactions. This tendency can be estimated on the basis of oil absorption parameters (OAPs). The empty space (void volume) between aggregates and agglomerates linked together through physical interactions and creating network can be expressed as the volume of dibutyl phthalate (DBP) absorbed by a given amount of filler (g DBP/100 g filler). Based on the OAP parameter measurement, the ability of LDHs with different $\mathrm{Mg} / \mathrm{Al}$ ratios to form "own structure" was estimated. The data

\begin{tabular}{llll}
\hline & LDH 30 & LDH 63 & LDH 70 \\
\hline $\mathrm{MgO}[\%]$ & 28.8 & 63.4 & 69.7 \\
$\mathrm{Al}_{2} \mathrm{O}_{3}[\%]$ & 71.2 & 36.6 & 30.3 \\
Surface area, $\mathrm{m}^{2} / \mathrm{g} \mathrm{BET}$, after activation $3 \mathrm{~h}$ at $550^{\circ} \mathrm{C}$ & 276 & 200 & 196 \\
Range of aggregates size [nm] (water medium) & $165-2253$ & $526-1056$ & $940-2118$ \\
Size of the main fraction [nm] (water medium) & 307 & 745 & 1332 \\
Percentage by number [\%] & 36 & 38 & 38 \\
Range of aggregates size, $\mathrm{nm}$ (paraffin oil) & $\leq 4698$ & $\leq 2125$ & $\leq 4863$ \\
$\begin{array}{l}\text { Oil absorption values OAV, g/100 g (dibutyl } \\
\text { phthalate) }\end{array}$ & 172.9 & 104.2 & 86.5 \\
d-Spacing, nm & & & 0.78 \\
\hline
\end{tabular}

Table 5. Characteristics of LDH containing different $\mathrm{Mg} / \mathrm{Al}$ ratios. 
from Table 5 confirmed that all LDH-30 show the tendency to create the structure similar to conventional silica with the value of surface area $\left(140 \mathrm{~m}^{2} / \mathrm{g}\right)$ [77].

From the X-ray diffraction analysis patterns, the interlayer distances were calculated using Bragg's equation and are presented in Table 5. All $\mathrm{Mg}-\mathrm{Al}-\mathrm{CO}_{3}-\mathrm{LDH}$ types filler featured a similar d-value of approximately $0.77 \mathrm{~nm}$, what should be noted the basal reflections of LDH30 were reduced compared with two other types of LDHs indicating a less-ordered, lesslamellar structure of particles.

Synthetic hydrotalcite (HT) with 14.1/4.5/42.2/39.2 atomic\% $\mathrm{Mg} / \mathrm{Al} / \mathrm{O} / \mathrm{C}$ ratio (indicated using XPS analysis) was modified using four different ionic liquids: didecyldimethylammonium saccharinate [DDA][Sac], didecyldimethylammonium acesulfamate [DDA][Ace], benzalkonium saccharinate $[\mathrm{BA}][\mathrm{Sac}]$, and benzalkonium acesulfamate [BA][Ace], according to the method described in Section 2.1. The surface properties of pristine HT are compiled in Table 6.

As compared to previously described LDH, hydrotalcite (HT) characterizes lower value of surface area and porosity. The pore size is in range of $0.65-80.51 \mathrm{~nm}$, with a maximum of pore radius distribution curve occurred at $1.08 \mathrm{~nm}$. The studies indicated lower tendency to agglomeration comparing to other fillers used, especially in polar medium water. Scanning electron microscopy (SEM) images at various magnifications for pristine HT are shown in Figure 1.

The size and shape of layered double hydroxide particles are usually depended on the synthesis method. Images of hydrotalcite particles revealed that HT-like fillers exhibit platy-like shape in the varied dimensions of sheets with lateral dimension $\leq 500 \mathrm{~nm}$, and occasionally up to $1.5 \mu \mathrm{m}$. Hexagonal platy particles stacked one on the top of each other and formed more aggregated structures due to the physical electrostatic interactions and hydrogen bonds. The modification with ionic liquids did not influence the particle tendency to agglomeration. The aggregated structures formed by various ionic liquid-modified HT in water were in range of $315-600 \mathrm{~nm}$, with the size of the main fraction $\pm 450 \mathrm{~nm}$ (percentage by number $40 \%$ ), in paraffin oil IL-HT formed larger aggregates up to $1.5 \mu \mathrm{m}$.

\begin{tabular}{ll}
\hline Surface area BET $\left[\mathrm{m}^{2} / \mathrm{g}\right]$ & 68 \\
\hline Volume of monolayer $\left[\mathrm{cm}^{3} / \mathrm{g}\right]^{*}$ & 14 \\
Specific volume of pores $\left[\mathrm{cm}^{3} / \mathrm{g}\right]^{* *}$ & 0.103 \\
Total amount of adsorbed nitrogen $\mathrm{N}_{2}\left[\mathrm{~cm}^{3} / \mathrm{g}\right]$ & 89.6 \\
Range of pores size $[\mathrm{nm}]$ & $0.65-80.51$ \\
Range of aggregate size $[\mathrm{nm}]($ water medium) & $295-526$ \\
Size of the main fraction $[\mathrm{nm}]$ (water medium) & 417 \\
Percentage by number $[\%]($ water medium) & 39 \\
Size of the main fraction $[\mathrm{nm}]$ (paraffin oil) & 2671 \\
Oil adsorption parameter OAP $[\mathrm{g} / 100 \mathrm{~g}]$ & 57.4 \\
\hline
\end{tabular}

Table 6. Characteristic of pristine, synthetic hydrotalcite HT. 
The structure of synthetic hydrotalcite HT and ionic liquid-modified IL-HT was characterized by X-ray diffraction patterns as it is shown for pristine HT in Figure 2.

XRD analysis of the unmodified HT structure revealed basal reflections (003) corresponding to a Bragg diffraction peak at $2 \theta=11.60^{\circ}$ and d-spacing of $0.76 \mathrm{~nm}$ (Figure 2). The modification with ionic liquids did not cause the intercalation of the layer, modified IL-HT showed $\mathrm{d}$-spacing $=0.76 \mathrm{~nm}$. Probably, the immobilization of modifying compound occurred only on the outer surface of the filler. Particles were modified using the regeneration method, HT was previously calcined. The rehydration with solution of ionic liquids was done in an air atmosphere what probably caused recarbonation with small size anions as $\mathrm{CO}_{3}{ }^{2-}$ instead of reconstruction of structure with anions as saccharinate and acesulfamate. Modified IL-HT formed slightly larger aggregates as is shown on SEM images (Figure 3) for didecyldimethylammonium acesulfamate-modified hydrotalcite [DDA][Ace]-HT and didecyldimethylammonium saccharinate-modified hydrotalcite [DDA][Sac].

The behavior during heating and thermal stability of layered double hydroxides was determined using thermogravimetric analysis. The thermal stability of LDHs is influenced by crystallinity, the composition of the brucite-like layer, the interlayer anions.

For the LDH-30, the first weight loss (13\%) occurred in the temperature range of $180-230^{\circ} \mathrm{C}$ and was attributed to dehydration, the removal of the intercalated water molecules. The second transition peak at $306^{\circ} \mathrm{C}$ in the temperature range of $255-355^{\circ} \mathrm{C}$ (DTG analysis) was due to dehydroxylation, the removal of hydroxyl groups from the brucite layers. The third peak at $407^{\circ} \mathrm{C}$ in the temperature range of $390-450^{\circ} \mathrm{C}$ was due to the completion of dehydroxylation and removal of interlayer carbonate anions $\mathrm{CO}_{2}$. Similar TGA/DTG curves as for LDH30 were revealed for hydrotalcite HT [DDT][Sac]-HT and [DDT][Ace]-HT (Figures 4 and 5, Table 7) compiles the weight loss (wt \%), char residue (wt\%), and the temperature ranges attributed to DTG peaks.

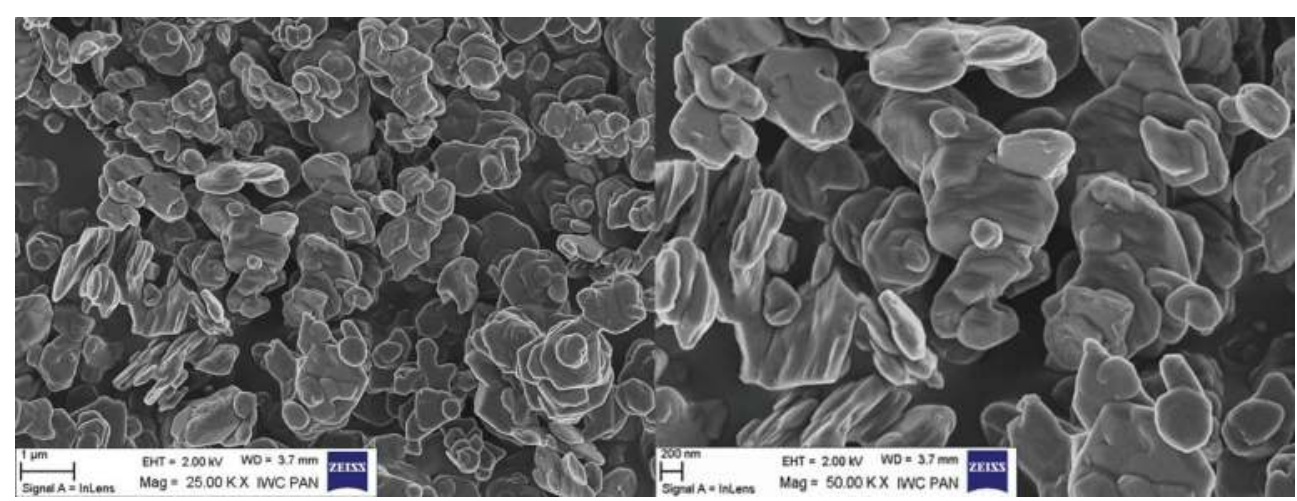

Figure 1. Characterization of the morphological structures. SEM images of hydrotlcite particles at various magnifications. 


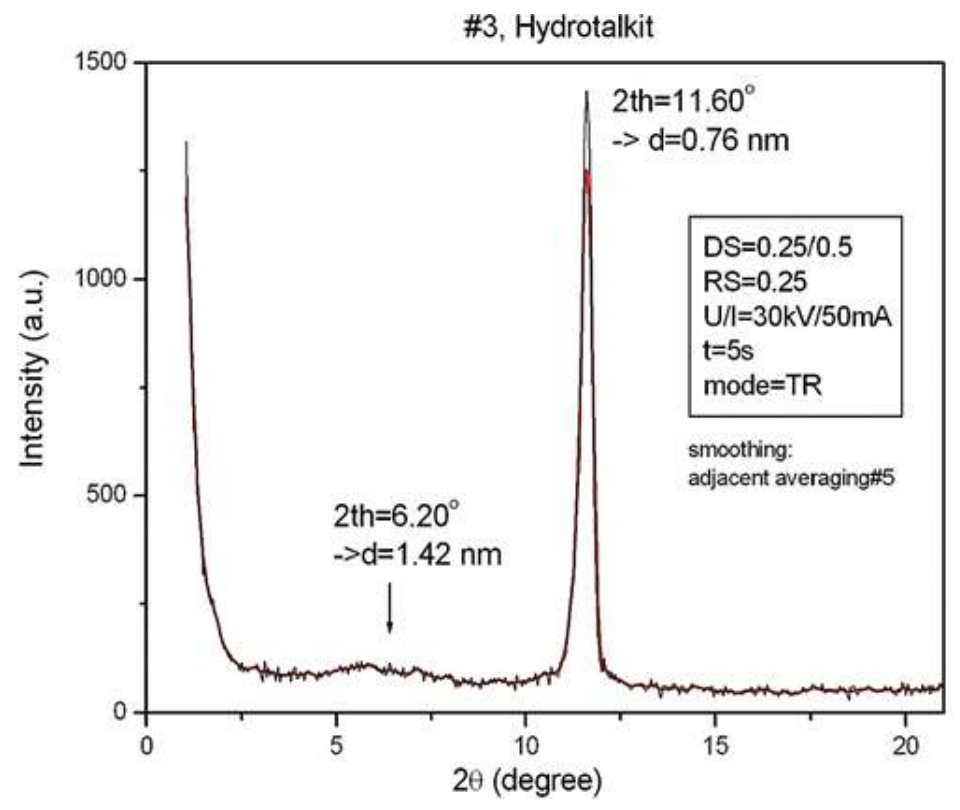

Figure 2. X-ray diffraction pattern of synthetic hydrotalcite HT.

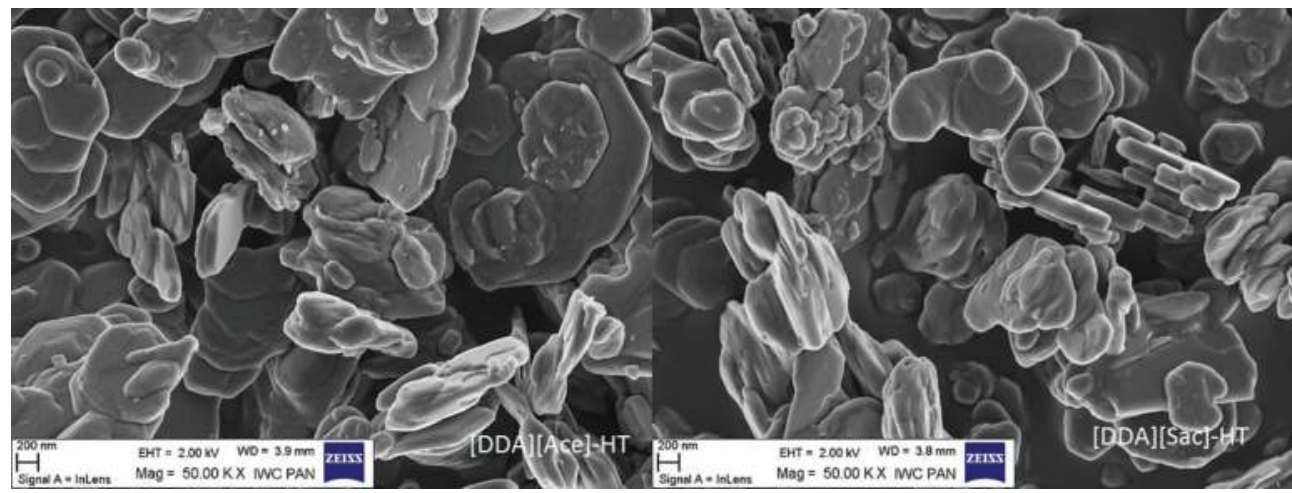

Figure 3. SEM images of [DDA][Ace]-HT and [DDA][Sac]-HT.

\subsection{Ionic liquids modified hydrotalcite IL-HT as a filler for hydrogenated nitrile rubber HNBR}

Table 8 shows the properties of hydrogenated nitrile rubber HNBR containing various HT loading. A significant improvement of mechanical properties of the polymer composite was related to filler loading. Effect occurred up to 10 parts of HT, higher amounts of hydrotalcite 


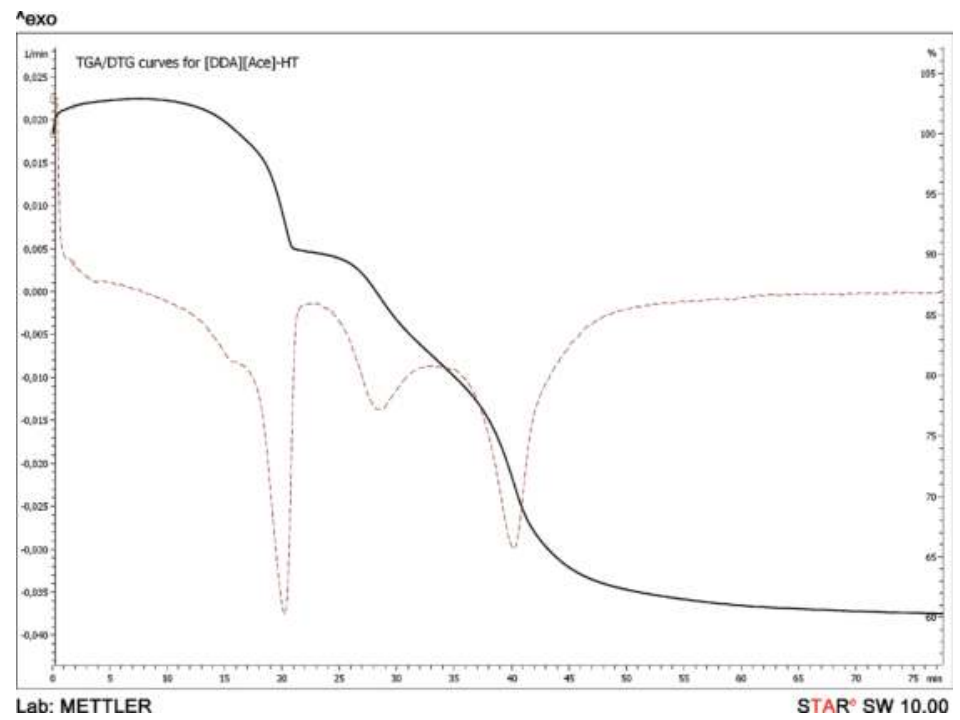

Figure 4. TGA/DTG curve for [DDA][Ace]-HT.

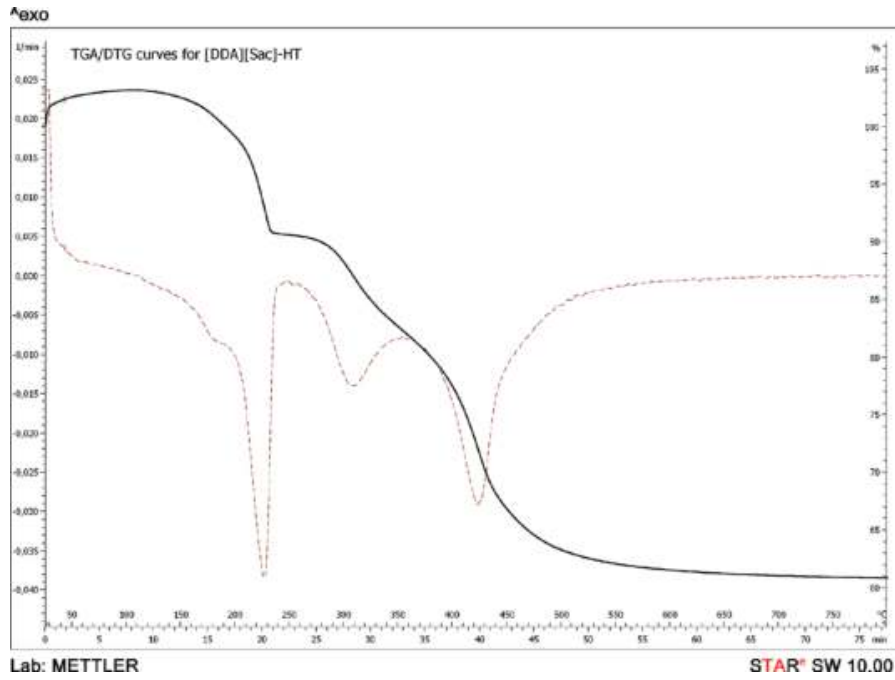

Figure 5. TGA/DTG curve for [DDA][Sac]-HT.

led to deterioration of mechanical properties as a result of uneven dispersion of clay in the matrix. Increasing clay loading influenced crosslink density of the vulcanizates, as a result of physical interactions between clay surface and polar functional group $-\mathrm{CN}$ in elastomer chains. Direct application of didecyldimethyl ammonium saccharinate and acesulfamate as 


\begin{tabular}{lllll}
\hline & LDH-30 & HT & [DDA][Ace]-HT & [DDA][Sac]-HT \\
\hline Temperature range of DTG peak $\left[{ }^{\circ} \mathrm{C}\right.$ ] & $189-231$ & $204-231$ & $199-236$ & $200-236$ \\
Temperature of peak maximum $\left[{ }^{\circ} \mathrm{C}\right.$ ] & 220 & 243 & 226 & 226 \\
Weight loss [wt $\%$ ] & 13.1 & 13.4 & 12.7 & 12.7 \\
Temperature range of DTG peak $\left[{ }^{\circ} \mathrm{C}\right.$ ] & $258-355$ & $259-365$ & $283-363$ & $259-363$ \\
Temperature of peak maximum $\left[{ }^{\circ} \mathrm{C}\right]$ & 306 & 314 & 307 & 307 \\
Weight loss [wt\%] & 7.4 & 7.6 & 7.9 & 9.6 \\
Temperature range of DTG peak $\left[{ }^{\circ} \mathrm{C}\right]$ & $353-564$ & $392-454$ & $397-451$ & $392-448$ \\
Temperature of peak maximum $\left[{ }^{\circ} \mathrm{C}\right]$ & 407 & 429 & 428 & 425 \\
Weight loss [wt $\%$ ] & 19.4 & 22.0 & 22.0 & 20.0 \\
Char residue [wt $\%$ ] & 60.1 & 57.0 & 57.4 & 57.7 \\
\hline
\end{tabular}

Table 7. Thermal stability of layered fillers determined by TGA/DTG.

a previously prepared pastes led to the enhancement of mechanical properties as a result of filler dispersion improvement. The long hydrocarbon chain presents in ionic liquid cations facilitated the compounding of rubber composites acting as plasticizing agents. Compared to vulcanizates containing unmodified hydrotalcite, a decrease of modulus at $100 \% \mathrm{SE}_{100}$ with a simultaneous increase in crosslink density $v_{t^{\prime}}$ tensile strength TS, and elongation at break $E_{b}$ for IL-HT/HNBR composites was observed what confirm that this way modified filler characterizes lower surface polarity, better dispersion in rubber matrix; on the other hand, the interactions with polar elastomer functional groups are still possible what resulted in the presence of physical crosslinks in the matrix. Application of HT influenced resistance of the composites during accelerated aging. Inorganic compounds such as metal oxides are known for their effective UV screening. The analysis of the aging coefficients indicated that a higher HT amount resulted in the UV and weathering stability. Effect was strongly evident for the IL-HT. This behavior may be explained by more uniform dispersion of the filler in the elastomer which resulted more effective UV screening.

Analysis of SEM images for vulcanizates containing HT and [DDA][Sac]-HT concluded that filler particles were distributed uniformly (Figure 6). The melt compounding method using a laboratory two-roll mill in the temperature about $40^{\circ} \mathrm{C}$ did not favor any preferential orientation of the layer and still some randomly distributed agglomerates with an average size of $3 \mu \mathrm{m}$ for pristine HT were detected.

\subsection{Curing studies, mechanical properties of IL-HT/XNBR composites}

$\mathrm{Mg}-\mathrm{Al}-\mathrm{LDH}$ are active fillers able to interact with $-\mathrm{COOH}$ functional groups. Addition of large quantities of LDH might cause difficulties in obtaining a homogenous dispersion. The melt-mixing method in industry scale usually is supported by the addition during processing plasticizers improving and able to facilitate the dispersion. It was anticipated that the incorporation of ILs may help decrease the size of aggregates formed in the XNBR matrix. 


\begin{tabular}{|c|c|c|c|c|c|c|c|c|}
\hline & $t_{90}[\mathrm{~min}]$ & $\Delta S^{\prime}[\mathrm{dNm}]$ & $\begin{array}{l}v_{t} \times 10^{5} \\
{\left[\mathrm{~mol} / \mathrm{dm}^{3}\right]}\end{array}$ & $\mathrm{SE}_{100}[\mathrm{MPa}]$ & TS [MPa] & $\mathrm{E}_{\mathrm{B}}[\%]$ & $\mathrm{K}_{\mathrm{uv}}$ & $\mathbf{K}_{\mathrm{w}}$ \\
\hline- & 20 & 21.8 & 2.5 & 0.85 & 10.3 & 808 & 0.24 & 0.22 \\
\hline HT, 5 phr & 19,7 & 31.5 & 7.7 & 1.26 & 14.0 & 570 & 0.28 & 0.26 \\
\hline HT, $10 \mathrm{phr}$ & 16,9 & 32.8 & 9.6 & 1.37 & 14.6 & 606 & 0.28 & 0.27 \\
\hline HT, $20 \mathrm{phr}$ & 15,0 & 31.9 & 13.7 & 1.47 & 15.8 & 578 & 0.32 & 0.36 \\
\hline $\begin{array}{l}\text { [DDA] }[\text { Sac]-HT, } \\
10 \mathrm{phr}\end{array}$ & 21,5 & 32.8 & 10.4 & 0.97 & 12.8 & 732 & 0.38 & 0.36 \\
\hline $\begin{array}{l}\text { [DDA][Ace]-HT, } \\
10 \mathrm{phr}\end{array}$ & 21,5 & 32.3 & 11.4 & 0.98 & 13.3 & 697 & 0.33 & 0.53 \\
\hline $\begin{array}{l}{ }^{*}[\mathrm{DDA}][\mathrm{Sac}] / \mathrm{HT}, \\
10 \mathrm{phr}\end{array}$ & 16,0 & 36.3 & 13.3 & 1.00 & 16.9 & 728 & 0.47 & 0.46 \\
\hline $\begin{array}{l}*[\mathrm{DDA}][\text { Ace }] / \mathrm{HT}, \\
10 \mathrm{phr}\end{array}$ & 17,5 & 31.1 & 14.4 & 0.97 & 15.2 & 720 & 0.49 & 0.42 \\
\hline$[\mathrm{BA}][\mathrm{Sac}]-\mathrm{HT}, 10 \mathrm{phr}$ & 20.0 & 32.3 & 13.9 & 0.92 & 16.8 & 678 & 0.37 & 0.32 \\
\hline [BA][Ace]-HT, $10 \mathrm{phr}$ & 20.5 & 35.3 & 15.8 & 0.94 & 16.5 & 700 & 0.54 & 0.55 \\
\hline
\end{tabular}

$t_{90^{\prime}}$ optimum cure time, $\Delta S^{\prime}$, torque increment; $v_{\mu^{\prime}}$ crosslink density; $\mathrm{SE}_{100^{\prime}}$ modulus at $100 \%$ strain; $\mathrm{TS}$, tensile strength; $\mathrm{K}$, aging coefficient; $\mathrm{K}_{\mathrm{UV}}$, $\mathrm{UV}$ treatment; $\mathrm{W}$, weathering aging.

*Application of ionic liquids, directly as a mixture with filler.

Table 8. Properties of HT/HNBR and IL-HT/HNBR composites.

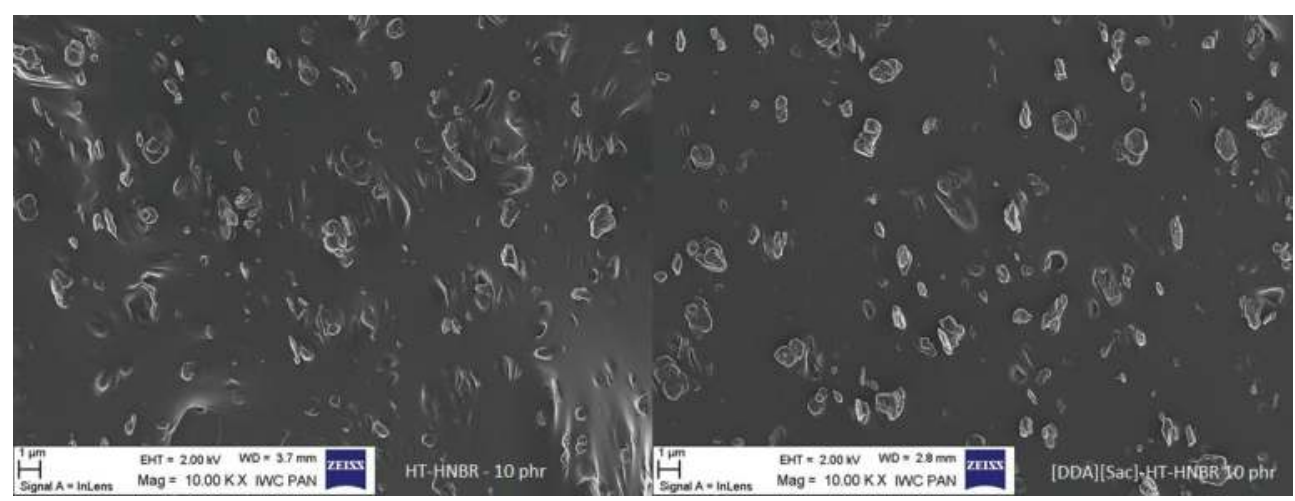

Figure 6. SEM images of HT/HNBR and [DDA][Sac]-HT/HNBR composites.

The IL-HT/XNBR composites were cured using nanoparticles of zinc oxide $\mathrm{ZnO}$. The properties of vulcanizates are compiled in Table 9. A strong influence of ionic liquids on the crosslink network density of XNBR rubber was observed. Ionic liquids act here as activators, increased crosslinking density. Probably in the presence of ionic liquids, the structure of formed clusters was more ordered containing a higher amount of ion pairs as well as nonionic hydrocarbon content. The influence of the ionic liquids, type of anion and cation on the crosslink density was observed. Hydrotalcites modified with ionic liquids containing saccharinate anion [DDA] 
[Sac]-HT and[BA][Sac]-HT increased the percentage of ionic crosslinks. As a result, the tensile strength of vulcanizates was almost decreased double. At the same time, such a modification did not affect the increase in stiffness. Additionally, as shown in Figures 7-9, the presence of long hydrocarbons segments in ILs cations exerted the plasticizing effect of IL-HT-based composites improving dispersion and caused the orientation of the layers of filler in the direction of the shear force during compounding.

Selected ionic liquids can be advantageously used to modify the hydrotalcite in order to obtain rubber vulcanizates XNBR characterized by excellent mechanical properties.

\begin{tabular}{|c|c|c|c|c|c|c|c|}
\hline & $t_{90}[\mathrm{~min}]$ & $\Delta S^{\prime}[\mathrm{dNm}]$ & $v_{t} \times 10^{5}\left[\mathrm{~mol} / \mathrm{dm}^{3}\right]$ & $\Delta v[\%]$ & $\mathrm{SE}_{100}[\mathrm{MPa}]$ & TS [MPa] & $\mathrm{E}_{\mathrm{B}}[\%]$ \\
\hline- & 31 & 6.50 & 9.6 & 16.8 & 1.27 & 11.8 & 693 \\
\hline HT, $10 \mathrm{phr}$ & 30 & 7.20 & 21.8 & 28.2 & 3.12 & 13.8 & 642 \\
\hline $\begin{array}{l}{[\mathrm{DDA}][\mathrm{Sac}] /} \\
\mathrm{HT}, 10 \mathrm{phr}\end{array}$ & 24 & 9.48 & 39.48 & 86.6 & 2.19 & 23.9 & 823 \\
\hline $\begin{array}{l}{[\mathrm{DDA}][\text { Ace }] /} \\
\mathrm{HT}, 10 \mathrm{phr}\end{array}$ & 24 & 7.10 & 28.77 & 39.2 & 2.17 & 21.6 & 706 \\
\hline $\begin{array}{l}{[\mathrm{BA}]} \\
{[\mathrm{Sac}]-\mathrm{HT},} \\
10 \mathrm{phr}\end{array}$ & 27 & 8.83 & 39.4 & 72.5 & 2.13 & 23.8 & 777 \\
\hline $\begin{array}{l}{[\mathrm{BA}][\text { Ace]- }} \\
\text { HT,10phr }\end{array}$ & 26 & 7.20 & 45.01 & 42.06 & 2.07 & 20.3 & 817 \\
\hline
\end{tabular}

$t_{90^{\prime}}$ optimum cure time; $\Delta S^{\prime}$, torque increment; $v_{t^{\prime}}$ crosslink density; $\Delta v$, ionic crosslinks number; $\mathrm{SE}_{100^{\prime}}$ modulus at $100 \%$ strain; TS, tensile strength.

Table 9. Properties of HT/XNBR and IL-HT/XNBR composites.

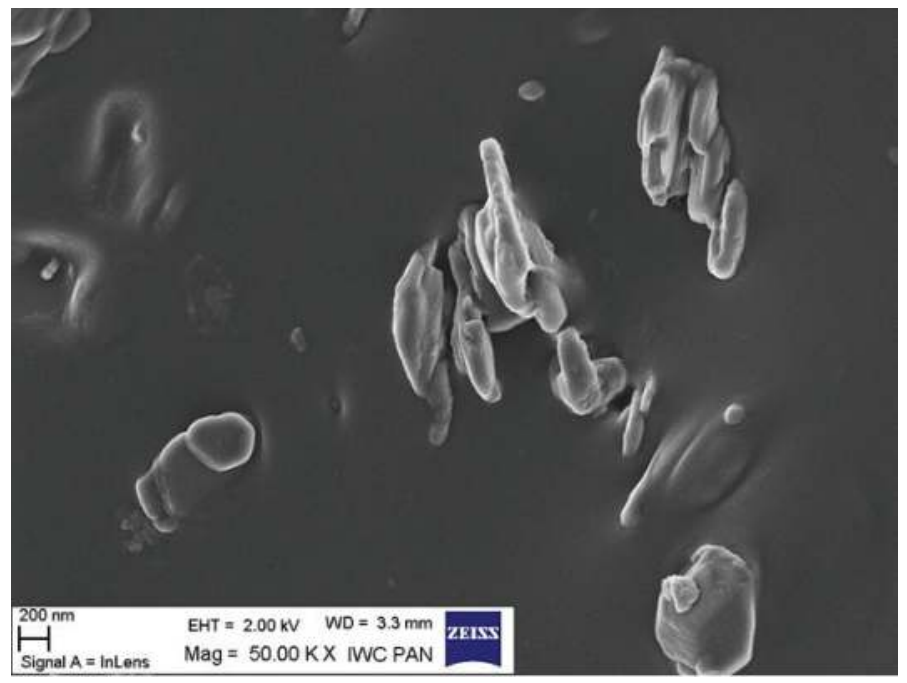

Figure 7. SEM image of HT-XNBR composite. 


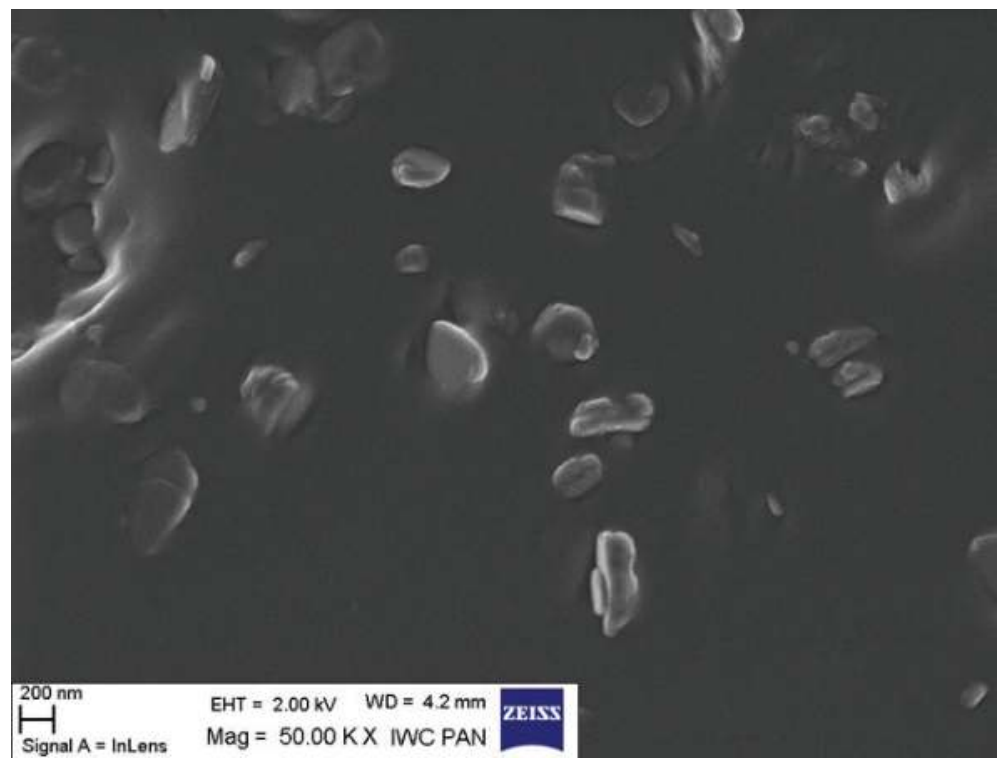

Figure 8. SEM image of [BA][Sac]-HT/XNBR composite.

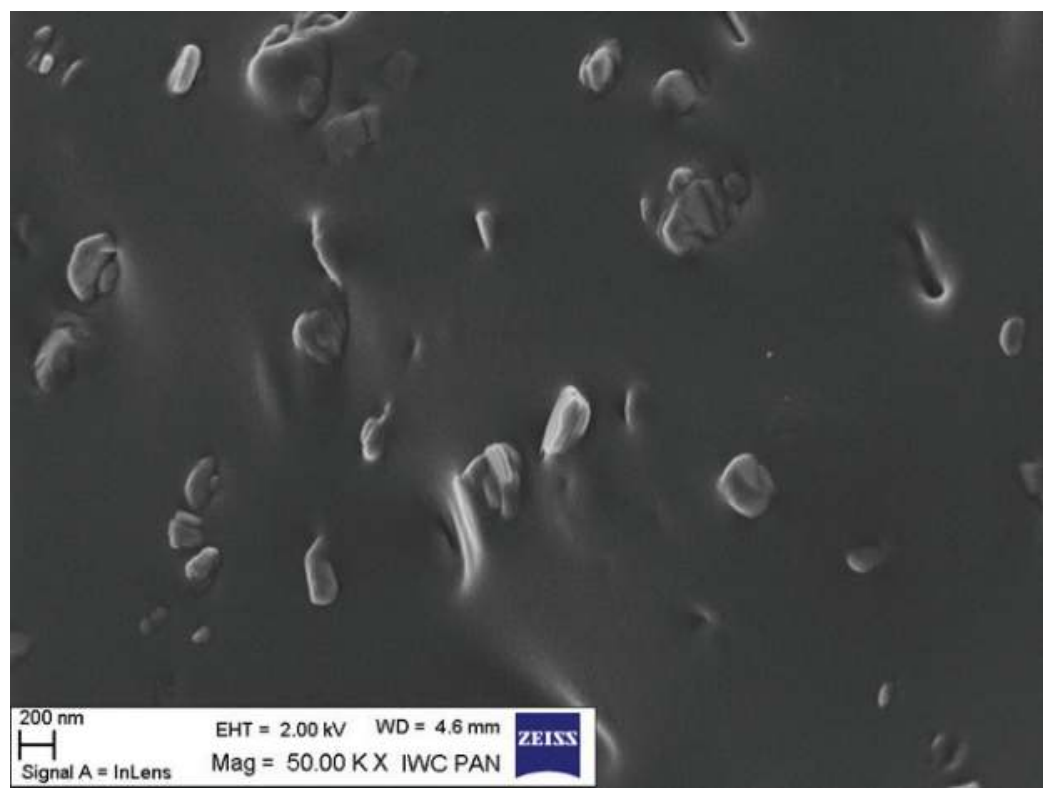

Figure 9. SEM image of [BA][Ace]-HT/XNBR composite. 


\subsection{Ionic elastomers based on carboxylated nitrile rubber XNBR and LDHs with various $\mathrm{Mg} / \mathrm{Al}$ ratios}

Carboxylated nitrile rubber composites containing LDH-30, LDH-63, and LDH-70 at various clay loadings (10, 20, and 30 parts per hundred rubber) were prepared according to method described in Section 2.3. The curing at various temperatures was investigated. Table 10 shows the parameters that describe the vulcanization reaction at three temperatures 150,160, and $170^{\circ} \mathrm{C}$ for XNBR containing $30 \mathrm{phr}$ of various LDH.

Every LDH used was able to cure carboxylated nitrile rubber when it was added to rubber mixture in content of 30 parts per hundred rubber. As the temperature was increased, the cure index rate CRI raised. The effect was stronger for the $\mathrm{LDH}-30$ with a lower $\mathrm{Mg} / \mathrm{Al}$ ratio indicating that ionic cluster formation is strongly induced by temperature.

Regarding the normalized elastic component $S^{\prime}$, which is the one that is usually taken as the vulcanization curve (Figure 10), it can be observed that at any temperature, the curve rises with reaction time, no reaching plateau. A reaction rate, in terms of the slope, in the first stage of the curve increases with temperature for LDH-63 and the maximum torque achieved higher value at $170^{\circ} \mathrm{C}$ than it took place for the temperature of $160^{\circ} \mathrm{C}$. The opposite effect was observed for $\mathrm{LDH}-70$ the filler with a higher $\mathrm{Mg} / \mathrm{Al}$ ratio. At lower temperatures $150^{\circ} \mathrm{C}$, the reaction is slower and the curves cannot achieve a plateau during the test time (120 min). Higher vulcanization temperature $170^{\circ} \mathrm{C}$ enhanced the reaction at the first stage, during first $30 \mathrm{~min}$, indicating a higher value of the elastic component $S^{\prime}$ (Figure 10) at this period as compared with values achieved at $170^{\circ} \mathrm{C}$. However, the maximum torque decreases with the increment in reaction temperature for LDH-70/XNBR composites. It should be taken into consideration that ionic bonds formed during reaction are thermally labile. If the curve that corresponds to the normalized viscous component $S^{\prime \prime}$ (Figure 11) is analyzed a different behavior occurred. For each temperature

\begin{tabular}{|c|c|c|c|c|c|c|c|c|}
\hline & \multicolumn{3}{|c|}{ LDH-30, $30 \mathrm{phr}$} & \multicolumn{2}{|c|}{ LDH-63, $30 \mathrm{phr}$} & \multicolumn{3}{|c|}{ LDH-70, 30 phr } \\
\hline & $150^{\circ} \mathrm{C}$ & $160^{\circ} \mathrm{C}$ & $170^{\circ} \mathrm{C}$ & $160^{\circ} \mathrm{C}$ & $170^{\circ} \mathrm{C}$ & $150^{\circ} \mathrm{C}$ & $160^{\circ} \mathrm{C}$ & $170^{\circ} \mathrm{C}$ \\
\hline$S_{\mathrm{H}^{\prime}}^{\prime} \mathrm{dNm}$ & 7.84 & 7.34 & 6.23 & 4.36 & 4.67 & 8.21 & 7.78 & 6.42 \\
\hline$S_{L^{\prime}}^{\prime} \mathrm{dNm}$ & 1.87 & 1.63 & 1.47 & 0.75 & 0.66 & 1.90 & 1.64 & 1.43 \\
\hline$\Delta S^{\prime}$ & 5.97 & 5.71 & 4.76 & 3.61 & 4.01 & 6.31 & 6.14 & 4.99 \\
\hline$t_{\Delta 2^{\prime}} \min$ & 10.21 & 6.35 & 4.81 & 34.16 & 16.58 & 11.66 & 1.17 & 0.62 \\
\hline$t_{50^{\prime}} \min$ & 18.68 & 11.12 & 6.34 & 28.92 & 16.63 & 23.89 & 13.95 & 6.58 \\
\hline$t_{90^{\prime}} \min$ & 80.18 & 68.07 & 47.96 & 116.88 & 101.29 & 115.90 & 101.79 & 55.56 \\
\hline$\left(t_{90}-t_{\Delta 2}\right), \min$ & 69.97 & 61.72 & 43.15 & 82.72 & 84.71 & 104.24 & 100.62 & 55.04 \\
\hline $\begin{array}{l}\text { CRI, 100/ } \\
\left(t_{90}-t_{\Delta 2}\right)\end{array}$ & 1.43 & 1.62 & 2.32 & 1.21 & 1.18 & 0.96 & 0.99 & 1.82 \\
\hline
\end{tabular}

Table 10. Vulcanization parameters as function of various LDHs and temperature of curing. 
growing curves, characteristics for ionic vulcanization are observed. It confirms that ionic bonds that are formed during reaction show thermal liability. Thermal liability and the breakage of the ionic associations cause the loss in elasticity of the sample ( $S^{\prime}$ values) at higher temperature and increment of the viscous component. Studies of crosslink density and mechanical properties of XNBR composites were performed for the vulcanizates cured at $160^{\circ} \mathrm{C}$.

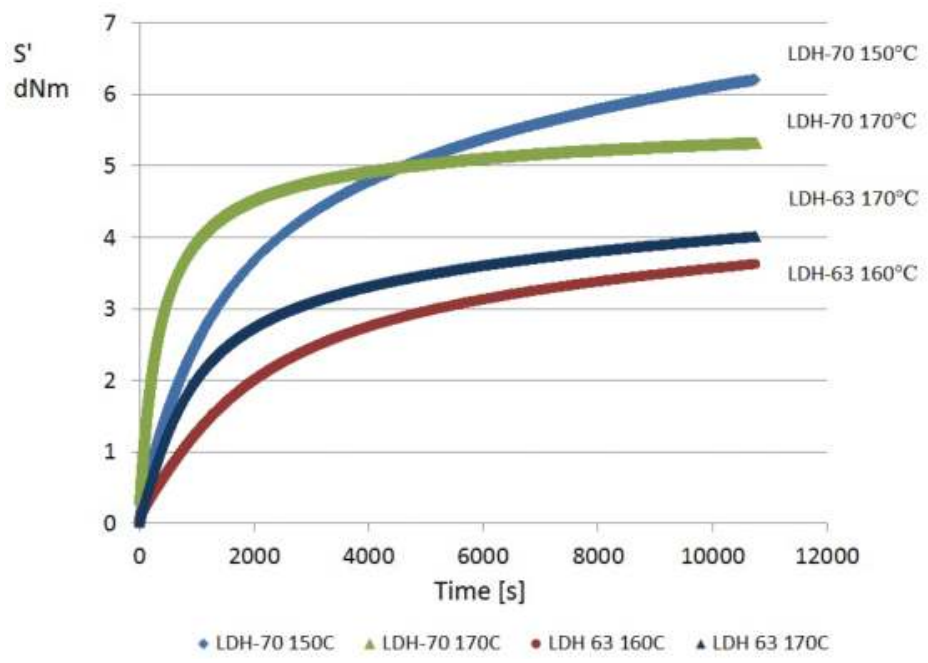

Figure 10. Normalized elastic component $\mathrm{S}^{\prime}(\mathrm{dNm})$ of the torque as a function of time for XNBR compounds crosslinked at various temperatures.

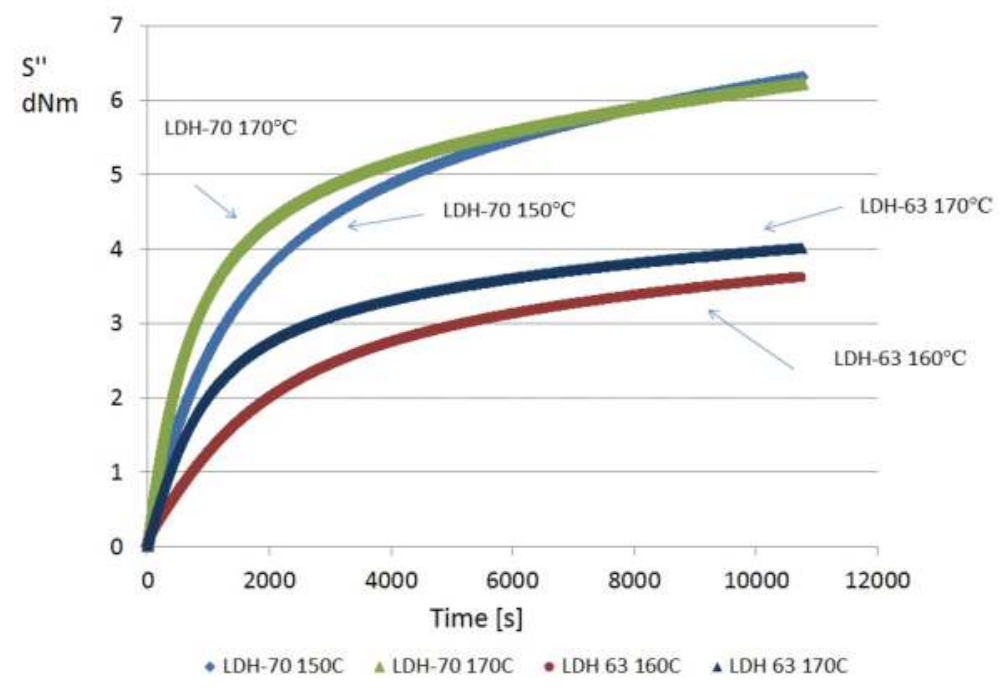

Figure 11. Normalized viscous component $\mathrm{S}^{\prime \prime}(\mathrm{dNm})$ of the torque as a function of time for XNBR compounds crosslinked at various temperatures. 
The influence of various LDH contents on the rubber properties was analyzed (Table 11).

The tensile measurement shown in Table $\mathbf{1 1}$ clearly indicates the reinforcement effect as a filler in carboxylate nitrile rubber. Both the high $\mathrm{Mg} / \mathrm{Al}$ ratio and filler concentration lead to improvement in tensile strength. The increase in tensile strength with the content of various LDH fillers is likely due to a change in crosslink density. It was also noted that the modulus at $100 \%$ increased with higher LDH content. The highest tensile strength was achieved in the case of an XNBR composite filled with LDH-70 containing the highest amount of magnesium.

\begin{tabular}{|c|c|c|c|c|}
\hline & $v_{t} \times 10^{5}\left[\mathrm{~mol} / \mathrm{dm}^{3}\right]$ & $\mathrm{SE}_{100}[\mathrm{MPa}]$ & TS [MPa] & $\mathrm{E}_{\mathrm{B}}[\%]$ \\
\hline $\begin{array}{l}\text { Cured with } 3 \text { phr } \\
\mathrm{ZnO}\end{array}$ & 9.6 & 1.27 & 11.8 & 693 \\
\hline LDH-30, $10 \mathrm{phr}$ & 2.2 & 1.21 & 3.9 & 974 \\
\hline LDH 30, 20 phr & 6.8 & 1.81 & 4.5 & 898 \\
\hline LDH 30,30 phr & 8.6 & 2.08 & 12.1 & 831 \\
\hline LDH-63, $10 \mathrm{phr}$ & 5.9 & 1.32 & 8.92 & 812 \\
\hline LDH-63, $20 \mathrm{phr}$ & 7.5 & 1.56 & 10.9 & 793 \\
\hline LDH-63, $30 \mathrm{phr}$ & 8.1 & 2.06 & 12.2 & 739 \\
\hline LDH-63, 30 phr** & 6.8 & 1.71 & 8.67 & 735 \\
\hline LDH-70, $10 \mathrm{phr}$ & 6.1 & 1.69 & 14.4 & 901 \\
\hline LDH -70, 20 phr & 8.4 & 1.86 & 15.6 & 912 \\
\hline LDH $-70,30 \mathrm{phr}$ & 12.9 & 2.00 & 16.2 & 901 \\
\hline LDH-70, 30 phr** & 7.1 & 1.82 & 9.81 & 743 \\
\hline
\end{tabular}

$v_{t^{\prime}}$ crosslink density; $\mathrm{SE}_{100^{\prime}}$ modulus at $100 \%$ strain; TS, tensile strength.

${ }^{*}$ Cured sample was cut and vulcanized again.

Table 11. Properties of LDH-30/XNBR, LDH-63/XNBR, and LDH-70/XNBR composites.

\section{Conclusions}

Layered double hydroxides are promising materials in the rubber industry. The presence of both unsaturated bonds and two functional groups nitrile and carboxyl in carboxylated nitrile rubber allows it to be crosslinked via conventional agents (such as sulfur and accelerators, metallic oxides (e.g., zinc oxide), organic and metallic peroxides.

This investigation shows that magnesium-rich LDH can be applied at once as a reinforcing filler and as a curing agent in a carboxylated elastomer. An interesting conclusion is that the application of $\mathrm{LDH} \mathrm{Mg-Al} \mathrm{as} \mathrm{a} \mathrm{filler} \mathrm{may} \mathrm{allow} \mathrm{the} \mathrm{amount} \mathrm{of} \mathrm{metal} \mathrm{oxide} \mathrm{curative} \mathrm{to} \mathrm{be} \mathrm{reduced}$ in XNBR compounds. This revelation is very essential from an ecological aspect because the European Union requires that the concentration of zinc oxide should be reduced as much as possible. When layered double hydroxides are used as an alternative to conventional curing 
systems, the production of mechanically strong and transparent elastomer composites without any supplementary additives is enabled that is an important ecological and economical advantage. It is huge benefit for layered double hydroxides (LDHs) to serve multifunctional suitability in elastomers, such as crosslinking substance, UV screener, thermal, mechanical, and barrier property enhancer. Simplicity of synthesis and easy way of surface modification with different anions give this filler highly tunable characteristics, the possibility to control filler structure and interlayer spacing. Study has demonstrated that the incorporation of layered double hydroxides can remarkably change elastomer properties. Layered double hydroxides were able to cure carboxylated nitrile rubber. The tensile measurements indicated the enhancement of mechanical properties. Magnesium-rich layered double hydroxides (LDHs) act as a reinforcing filler and as a curing agent in carboxylated elastomers. Application of ionic liquids consisting of saccharinate and acesulfamate ions as surface functionalizing agents for layered double hydroxide enhanced dispersion and compatibility of nanoparticles in an elastomer matrix. Ionic liquids facilitated the compounding of nitrile rubber acting as plasticizing agents and influenced ionic clusters formation, resulting in increase of crosslink density.

\section{Author details}

Magdalena Lipińska

Address all correspondence to: magdalena.lipinska@p.lodz.pl

Institute of Polymer and Dye Technology, Lodz University of Technology, Stefanowskiego, Łódź, Poland

\section{References}

[1] Leroux F, Besse JP. Polymer interleaved layered double hydroxide: A new emerging class of nanocomposites. Chemistry of Materials. 2001;13:3507-3515. DOI: 10.1021/cm0110268

[2] Wang GA, Wang CC, Chen CY. The disorderly exfoliated LDHs/PMMA nanocomposite synthesized by in situ bulk polymerization. Polymer. 2005;46:5065-5074. DOI: 10.1016/j. polymer.2005.04.054

[3] Hsueh HB, Chen CY. Preparation and properties of LDHs/epoxy nanocomposites. Polymer.2003;44:5275-5283. DOI: 10.1016/S0032-3861(03)00579-2

[4] PradhanS, Costa FR, WagenknechtU, Jehnichen D, BhowmickAK, Heinrich G. Elastomer/ LDH nanocomposites: Synthesis and studies on nanoparticle dispersion, mechanical properties and interfacial adhesion. European Polymer Journal. 2008;44:3122-3132. DOI: 10.1016/j.eurpolymj.2008.07.025

[5] Zammarano M, Bellayer S, Gilman JW, Franceschi M, Beyer FL, Harris RH, Meriani S. Delamination of organo-modified layered double hydroxides in polyamide 6 by melt processing. Polymer. 2006;47:652-662. DOI: 10.1016/j.polymer.2005.11.080 
[6] Li YC, Yang YH, Shields JR, Davis RD. Layered double hydroxide-based fire resistant coatings for flexible polyurethane foam. Polymer. 2015;56:284-292. DOI: 10.1016/j. polymer.2014.11.023

[7] Wang L, Shengpei S, Chen D, Wilkie CA. Variation of anions in layered double hydroxides: Effects on dispersion and fire properties. Polymer Degradation and Stability. 2009;94:770-781. DOI: 10.1016/j.polymdegradstab.2009.02.003

[8] Laskowska A, Lipińska M, Zaborski M. Hydrotalcite as a filler for carboxylated nitrile rubber. Przemysł Chemiczny. 2011;90(5):878-882

[9] Laskowska A, Lipińska M, Zaborski M. Properties of carboxylated nitrile elastomer containing hydrotalcites with varying $\mathrm{Mg} / \mathrm{Al}$ ratio. In: Boudenne $\mathrm{A}$, editor. Proceedings of Nanocomposite 2011, Multiphase Polymers and Polymer Composites, Conference and Training School; 07-10 June 2011; Paris-Est University, France. Paris, France: Paris-Est University; 2011

[10] Del Hoyo C. Layered double hydroxides and human health: An overview. Applied Clay Science. 2007;36:103-121. DOI: 10.1016/j.clay.2006.06.010

[11] Mills SJ, Christy AG, Genin JMR, Kameda T, Colombo F. Nomenclature of the hydrotalcite supergroup: Natural layered double hydroxides. Mineralogical Magazine. 2012;76(5): 1289-1336

[12] Xu PZ, Zhang J, Adebajo MO, Zhang H, Zhou C. Catalytic applications of layered double hydroxides and derivatives. Applied Clay Science. 2011;53:139-150. DOI: 10.1016/j. clay.2011.02.007

[13] Leroux F, Adachi-Pagano M, Intissar M, Chauviere S, Forano C, Besse JP. Delamination and restacking of layered double hydroxides. Journal of Materials Chemistry. 2001; 11:105-112. DOI: 10.1039/b002955f

[14] Ogawa M, Kaiho H. Homogeneous precipitation of uniform hydrotalcite particles. Langmuir. 2002;18:4240-4242. DOI: 10.1021/la0117045

[15] Ramos E, Lopez T, Bosch P, Asmoza M, Gomez R. Thermal stability of sol-gel hydrotalcites. Journal of Sol-Gel Science and Technology. 1997;8:437-442. DOI: 10.1007/ BF02436879

[16] Kovanda F, Jindova E, Lang K, Kubat P, Sedlakowa Z. Preparation of layered double hydroxides intercalated with organic anions and their application in LDH/poly(butyl methacrylate) nanocomposites. Applied Clay Science. 2010;48(1-2):260-270. DOI: 10.1016/j. clay.2009.11.012

[17] Depege C, El Metoui FZ, Forano C, de Roy A, Dupuis J. Polymerization of silicates in layered double hydroxides. Chemistry of Materials. 1996;8(4):952-960. DOI: 10.1021/ cm950533k

[18] Zhu J, Yuan P, He H, Frost R, Tao Q, Shen W, Bostrom T. In-situ synthesis of surfactant/ silane modified hydrotalcites. Journal of Colloid and Interface Science. 2008;319:498-504. DOI: $10.1016 /$ j.jcis.2007.11.037 
[19] Kutlu B, Leuteritz A, Boldt R, Jehnichen D, Heinrich G. Effect of LDH synthesis and modification on the exfoliation and introduction of a robust anion-exchange procedure. Chemical Engineering Journal. 2014;243:394-404. DOI: 10.1016/j.cej.2014.01.026

[20] Hibino T. A new method for preparation of nanoplates of $\mathrm{Zn}-\mathrm{Al}$ layered double hydroxides. Applied Clay Science. 2011;54:83-89. DOI: 10.1016/j.clay.2011.07.016

[21] Brei VV, Melezhyk OV, Starukh GM, Oranskaya EI, Mutovkin PA. Organic precursor synthesis of Al-Mg mixed oxides and hydrotalcites. Microporous and Mesoporous Materials. 2008;113:411-417. DOI: 10.1016/j.micromeso.2007.11.040

[22] Zhelud kevich ML, Poznyak SK, Rodrigues LM. Raps D, Hack T, Dick LF, et al. Active protection coatings with layered double hydroxide nanocontainers. Corrosion Science. 2010;52:602-611. DOI: 10.1016/j.corsci.2009.10.020

[23] Arizaga GGC, Mangrich AS, da Costa Gardolinski JEF, Wypych F. Chemical modification of zinc hydroxide with dicarboxylic acids. Journal of Colloid and Interface Science. 2008;320:168-176. DOI: 10.1016/j.jcis.2007.12.038

[24] Li M, Guo Q. The preparation of the hydrotalcite-based composite phase change material. Applied Energy. 2015;156:207-212. DOI: 10.1016/j.apenergy.2015.07.040

[25] Longo P, Guerra G. Layered double hydroxides with low Al content and new intercalate structures. Applied Clay Science. 2013;71:27-31. DOI: 10.1016/j.clay.2012.10.016

[26] Costa FR, Leuteritz A, Wagenknecht U, Jehnichen D, Häußler L, Heinrich G. . Intercalation of Mg-Al double hydroxide by anionic surfactants: Preparation and characterization. Applied Clay Science. 2008;38(3):153-164. DOI: 10.1016/j.clay.2007.03.006

[27] Ha JU, Xanthos M. Novel modifiers for layered double hydroxides and their effects on the properties of polylactic acid composites. Applied Clay Science. 2010;47(3-4):303-310. DOI: 10.1016/j.clay.2009.11.033

[28] Costa FR, Pradhan S, Wagenknecht U, Bhowmick AK, Heinrich G. XNBR/LDH nanocomposites: Effect of vulcanization and organic modifier on nanofiller dispersion and strain-induced crystallization. Journal of Polymer Science: Part B: Polymer Physics. 2010;48:2302-2311. DOI: 10.1002/polb.22116

[29] Zhou CH. Emerging trends and challenges in synthetic clay-based materials and layered double hydroxides. Applied Clay Science. 2010;48(1-2):1-4. DOI: 10.1016/j. clay.2009.12.018

[30] Khan AI, O'Hare D. Intercalation chemistry of layered double hydroxides: Recent developments and application. Journal of Materials Chemistry. 2002;12:3191-3198. DOI: 10.1039/B204076

[31] Lipińska M, Zaborski M. The properties of butadiene-acrylonitrile rubber NBR filled with modified layered fillers. In: Book of abstracts 15th European Conference on Composite Materials; 24-28 June 2012; Venice, Italy. 2012. p. abstract ID 1355 
[32] Acharya H, Srivastava SK, Bhowmick AK. Synthesis of partially exfoliated EPDM/LDH nanocomposites by solution intercalation: Structural characterization and properties. Computer Science and Technology. 2007;67(13):2807-2816. DOI: 10.1016/j.compscitech. 2007.01.030

[33] Guo S, Zhang C, Peng H, Wang W, Liu T. Structural characterization, thermal and mechanical properties of polyurethane/CoAl layered double hydroxide nanocomposites prepared via in-situ polymerization. Computer Science and Technology. 2011;71(6):791-796. DOI: 10.1016/j.compscitech.2010.12.001

[34] Kotal M, Srivastava SK, Bhowmick AK. Thermoplastic polyurethane and nitrile butadiene rubber blends with layered double hydroxide nanocomposites by solution blending. Polymer International. 2010;59(1):2-10. DOI: 10.1002/pi.2686

[35] Pradhan B, Srivastava SK, Ananthakrishnan R, Saxena A. Preparation and characterization of exfoliated layered double hydroxide/silicone rubber composites. Journal of Applied Polymer Science. 2011;119(1):343-351. DOI: 10.1002/app.32614

[36] Das A, Costa FR, Wagenknecht U, Heinrich G. Nanocomposites based on chloroprene rubber: Effect of chemical nature and organic modification of nanoclay on the vulcanizate properties. Journal of European Polymer. 2008;44(11):3456-3465. DOI: 10.1016/j. eurpolymj.2008.08.025

[37] Thakur V, Das A, Mahaling RN, Rooj S, Gohs U, Wagenknecht U.et al. Influence of layered double hydroxides on the curing of carboxylated nitrile rubber with zinc oxide. Macromolecular Materials and Engineering. 2009;294(9):561-569. DOI: 10.1002/ mame.200900083

[38] Das A, Wang DY, Leuteritz A, Subramaniam K, Greenwell HC, Wagenknecht U, et al. Preparation of zinc oxide free, transparent rubber nanocomposites using a layered double hydroxide filler. Journal of Materials Chemistry. 2011;21:7194-7200. DOI: 10.1039/ c0jm03784b

[39] Das A, Wang DY, Stoeckelhubner KW, Jurk R, Fritzche J, Kluppel M, et al. Rubber-clay nanocomposites: Some recent results. In: Heinrich G, editor. Advanced Rubber Composition Advances in Polymer Science. Vol. 239. Berlin Heidelberg: Springer-Verlag; 2010. pp. 85-166. DOI: 10.1007/12_2010_96

[40] Kumar S, Das CK. Stearate modification of layered double hydroxide (LDH) for polyurethane elastomeric nanocomposites. Elastomery. 2010;14(4):15-22.

[41] Kulia T, Srivastava SK, Bhowmick AK. Rubber/LDH nanocomposites by solution blending. Journal of Applied Polymer Science. 2009;111:635-641. DOI: 10.1002/app.29117

[42] Reinert L, Batouche K, Lévêque J-M, Muller F, Bény J-M, Kebabi B, et al. Adsorption of imidazolium and pyridinium ionic liquids onto montmorillonite: Characterization and thermodynamic calculation. Chemical Engineering Journal. 2012;209:13-19. DOI: 10.1016/j.cej.2012.07.128 
[43] Lv G, Li Z, Jiang WT, Chang PH, Liao L. Interlayer configuration of ionic liquids in Ca-montmorillonite as evidenced by FTIR, TG-DT, and XRD analyses. Material Chemistry Physics. 2015;162:417-424. DOI: 10.1016/j.matchemphys.2015.06.008

[44] Livi S, Duchet-Rumeau J, Gerard JF. Supercritical $\mathrm{CO}_{2}$-ionic liquid mixture for modification of organoclays. Journal of Colloid and Interface Science. 2011;353:225-230. DOI: 10.1016/j.jcis.2010.09.049

[45] Kim NH, Malhotra SV, Xanthos M. Modification of cationic nanoclay with ionic liquids. Microporous and Mesoporous Materials. 2006;96:29-35. DOI: 10.1016/j.micromeso. 2006.06.017

[46] Lawal IA, Moodley B. Synthesis, characterization and application of imidazolium based ionic liquid modified montmorillonite sorbents for the removal of amaranth dye. RSC Advances. 2015;5:61913-61924. DOI: 10.1039/c5ra09483f

[47] Takahashi N, Hata H, Kuroda K. Anion exchangeable layered silicates modified with ionic liquids on the interlayer surface. Chemistry of Materials. 2010;22:3340-3348. DOI: $10.1021 / \mathrm{cm} 9037439$

[48] Hough-Troutman WL, Smiglak M, Griffin S, Reichert WM, Mirska I, Jodynis-Liebert J, et al. Ionic liquids with dual biological function: Sweet and anti-microbial, hydrophobic quaternary ammonium-based salts. New Journal of Chemistry. 2009;33:26-33. DOI: $10.1039 / \mathrm{b} 813213 \mathrm{p}$

[49] Lipińska M, Laskowska A, Zaborski M. Elastomer composites containing layered fillers modified with ionic liquids. Materials Science Forum. 2012;714:73-78. DOI: 10.4028/ www.scientific.net/MSF.714.73

[50] Marzec A, Laskowska A, Boiteux G, Zaborski M, Gain O, Serghei A. Properties of carboxylated nitrile rubber/hydrotalcite composites containing imidazolium ionic liquids. Macromolecular Symposia. 2014;341:7-17. DOI: 10.1002/masy.201300149

[51] Laskowska A, Marzec A, Boiteux G, Zaborski M, Gain O, Serghei A. Effect of imidazolium ionic liquid type on the properties of nitrile rubber composites. Polymer International. 2013;62:1575-1582. DOI: 10.1002/pi.4550

[52] Acharya H, Srivastava SK, Bhowmick AK. A solution blending route to ethylene propylene diene terpolymer/layered double hydroxide nanocomposites. Nanoscale Research Letters. 2007;2(1):1-5. DOI: 10.1007/s11671-006-9020-x

[53] Kumar B, Rana S, Singh RP. Photo-oxidation of EPDM/layered double hydroxides composites: Influence of layered double hydroxides and stabilizers. eXPRESS Polymer Letters. 2007;1(11):748-754. DOI: 10.3144/expresspolymlett.2007.103

[54] Maciejewska M, Zaborski M, Krzywania-Kaliszewska A. Mineral oxides and layered minerals in combination with itaconic acid as coagents for peroxide crosslinking of hydrogenated acrylonitrie-butadiene elastomer. Comptes Rendus Chimie. 2012;15:414423. DOI: 10.1016/j.crci.2012.01.001 
[55] Laskowska A, Zaborski M, Boiteux G, Gain O, Marzec A, Maniukiewicz W. Ionic elastomers based on carboxylated nitrile rubber (XNBR) and magnesium aluminium layered double hydroxide (hydrotalcite). eXPRESS Polymer Letters. 2014;8(6):374-386. DOI: 10.3144/expresspolymlett.2014.42

[56] Zhang M, Ding P, Du L, Qu B. Structural characterization and related properties of EVA/ZnAl-LDH nanocomposites prepared by melt and solution intercalation. Materials Chemistry and Physics. 2008;109:206-211. DOI: 10.1016/j.matchemphys.2007.11.013

[57] Leggat RB, Taylor SA, Taylor SR. Adhesion of epoxy to hydrotalcite conversion coatings: I. Correlation with wettability and electrokinetic measurements. Colloids Surface A: Physicochemical Engineering Aspects. 2002;210:69-81.

[58] Leggat RB, Taylor SA, Taylor SR. Adhesion of epoxy to hydrotalcite conversion coatings: II. Surface modification with ionic surfactants. Colloids and Surface A: Physicochemical and Engineering Aspects. 2002;210:83-94.

[59] Kotal M, Srivastava SK. Structure-property relationship of polyurethane/modified magnesium aluminium layered double hydroxide nanocomposites. Journal of Plastics Technology. 2011;15:61-68. DOI: 10.1007/s12588-011-9006-0

[60] Laskowska A, Zaborski M, Boiteux G, Gain O, Marzec A. Effect of unmodified layered double hydroxides MgAl-LDHs with various structures on the properties of filled carboxylated acrylonitrile-butadiene rubber XNBR. European Polymer Journal. 2014;60:172185. DOI: 10.1016/j.eurpolymj.2014.09.013

[61] Heideman G, Noordermeer JWM, Datta RN, Van Baarle B. Effect of zinc complexes as activator for sulfur vulcanization in various rubbers. Rubber Chemistry and Technology. 2005;78:245-257. DOI: 10.5254/1.3547881

[62] Basu D, Das A, Stoeckelhuber KW, Wagenknecht U, Heinrich G. Advances in layered double hydroxide (LDH)-based elastomer composites. Progress in Polymer Science. 2014;39:594-626. DOI: 10.1016/j.progpolymsci.2013.07.011

[63] Wang DY, Das A, Leuteritz A, Mahaling RN, Jehnichen D, Wagenknecht U, et al. Structural characteristics and flammability of fire retarding EPDM/layered double hydroxide (LDH) nanocomposites. RSC Advances. 2012;2:3927-3933. DOI: 10.1039/ C2RA20189E

[64] Das A, George JJ, Kutlu B, Leuteritz A, Wang DY, Rooj S, et al. A novel thermotropic elastomer based on highly filled LDH-SSB composites. Macromolecular Rapid Communication. 2012;33:337-342. DOI: 10.1002/marc.201100735

[65] Pradhan B, Srivastava SK, Bhowmick AK, Saxena A. Effect of bilayered stearate ion-modified $\mathrm{Mg}$-Al layered double hydroxide on the thermal and mechanical properties of silicone rubber nanocomposites. Polymer International. 2012;61:458-465. DOI: 10.1002/pi.3218

[66] Basu D, Das A, Stoeckelhuber KW, Jehnichen D, Formanek P, Sarlin E, et al. Evidence for an is situ developed polymer phase in ionic elastomers. Macromolecules. 2014;47:34363450. DOI: $10.1021 / \mathrm{ma} 500240 \mathrm{v}$ 
[67] Ibarra L, Rodriguez A, Mora-Barrantes I. Crosslinking of unfilled carboxylated nitrile rubber with different systems: Influence on properties. Journal of Applied Polymer Science. 2008;108:2197-2205. DOI: 10.1002/app.27893

[68] Ibarra L, Alzorriz M. Ionic elastomers based on carboxylated nitrile rubber (XNBR) and zinc peroxide: Influence of carboxylic group content on properties. Journal of Applied Polymer Science. 2002;84:605-615.

[69] Ibarra L, Rodriguez A, Mora-Barrantes I. Crosslinking of carboxylated nitrile rubber (XNBR) induced by coordination with anhydrous copper sulfate. Polymer International. 2009;58:218-226. DOI: 10.1002/pi.2519

[70] Ibarra L, Alzorriz M. Ionic elastomers based on carboxylated nitrile rubber and magnesium oxide. Journal of Applied Polymer Science. 2006;103:1894-1899. DOI: 10.1002/ app. 25411

[71] Ibarra L, Rodriguez A, Mora I. Ionic nanocomposites based on XNBR-OMg filled with layered nanoclay. European Polymer Journal. 2007;(43):753-761. DOI: 10.1016/j. eurpolymj.2006.12.007

[72] Ibarra L, Alzorriz M. Ionic elastomers based oncarboxylated nitrile rubber and calcium oxide. Journal of Applied Polymer Science. 2003;87:805-813.

[73] Laskowska A, Lipińska M, Zaborski M. Properties of carboxylated nitrile elastomer contained hydrotalcites with varying $\mathrm{Mg} / \mathrm{Al}$ ratio. Journal of Engineering Technology. 2011;2(1):24-33.

[74] Flory PJ, Rehner J. Statistical mechanics of cross-linked polymer networks. II. Swelling. Journal of Chemistry and Physics. 1943;11:521-526. DOI: 10.1063/1.1723792

[75] Przybyszewska M, Zaborski M. The effect of zinc oxide nanoparticle morphology on activity in crosslinking of carboxylated nitrile elastomer. eXPRESS Polymer Letters. 2009;3:542-552. DOI: 10.3144/expresspolymlett.2009.68

[76] Mandal UK, Tripathy DK, De SK. Dynamic mechanical spectroscopic studies on plasticization of an ionic elastomer based on carboxylated nitrile rubber by ammonia. Polymer. 1996;37:5739-5742. DOI: 10.1016/S0032-3861(96)00545-9

[77] Blume A. Analytical properties of silica-a key for understanding silica reinforcement. Kautschuk Gummi Kunstoffe. 2000;53(6):338-345. 